\title{
A Cell Atlas of Microbe-Responsive Processes in the Zebrafish Intestine
}

Reegan J. Willms ${ }^{1}$, Jennifer C. Hocking ${ }^{2}$ and Edan Foley ${ }^{1 *}$.

1: Department of Medical Microbiology and Immunology, Faculty of Medicine and Dentistry, University

of Alberta, Edmonton, AB, Canada

2: Division of Anatomy, Department of Surgery, Faculty of Medicine and Dentistry, University of Alberta,

Edmonton, AB, Canada

*Corresponding Author: efoley@ualberta.ca 


\begin{abstract}
Gut microbial products direct growth, differentiation and development in the animal host. Disruptions to host-microbe interactions have profound health consequences, that include onset of chronic inflammatory illnesses. However, we lack system-wide understanding of cell-specific responses to the microbiome. We profiled transcriptional activity in individual cells from the intestine, and associated tissue, of zebrafish larvae that we raised in the presence, or absence, of a microbiome. We uncovered extensive cellular heterogeneity in the conventional zebrafish intestinal epithelium, including previously undescribed cell types with known mammalian homologs. By comparing conventional to germ-free profiles, we mapped microbial impacts on transcriptional activity in each cell population. We revealed intricate degrees of cellular specificity in host responses to the microbiome, that included regulatory effects on patterning, metabolic and immune activity. For example, we showed that removal of microbes hindered transduction of vascular endothelial growth factor-dependent signals in the developing vasculature, resulting in impaired intestinal vascularization. Our work provides a high-resolution atlas of intestinal cellular composition in the developing fish gut and details the effects of the microbiome on each cell type.
\end{abstract}




\section{INTRODUCTION}

Research conducted with a variety of model organisms has revealed much about the importance of gut microbes for host health. Animals raised in sterile, germ-free environments, frequently exhibit defects in growth, immunity and metabolism (Bates et al., 2006; Hooper et al., 2001; Rawls et al., 2004; Reikvam et al., 2011). Of equal importance, sudden changes in composition or distribution of gut microbial communities are associated with severe and sometimes deadly illnesses, including gastrointestinal cancers and inflammatory bowel diseases (Belkaid and Hand, 2014; Zitvogel et al., 2015). Thus, it is critical to fully understand how the microbiota impacts development, growth, and cellular function of host organisms.

In recent years, zebrafish larvae have emerged as a valuable tool to characterize molecular and cellular regulators of host-microbe interactions (Brugman, 2016; Flores et al., 2020). Zebrafish develop within a protective chorion that shields them from environmental microbes up to forty-eight hours post fertilization. Once larvae exit the chorion, water-borne microbes colonize the gut lumen (Bates et al., 2006; Stephens et al., 2016; Wallace et al., 2005), where they influence development of host intestinal and extra-intestinal tissues (Bates et al., 2006; Cheesman et al., 2011; Kanther et al., 2011; Koch et al., 2018). From a technical perspective, zebrafish offer several advantages to pinpoint key events in developmental responses to the microbiota. Larvae are amenable to sophisticated genetic manipulations, including genetic modifications from the single cell stage (Grunwald and Eisen, 2002). Additionally, researchers have established simple protocols to generate large numbers of germ-free larvae, or larvae associated with defined microbial communities (Melancon et al., 2017; Pham et al., 2008), and the translucent epidermis is ideal for visualization of internal structures in fixed or live samples. Thus, zebrafish provide a convenient window to visualize microbial controls of vertebrate physiology.

Importantly, genetic regulation of intestinal function is highly similar between zebrafish and mammals. In both systems, orthologous signals, including those driven by Notch, BMP and Wnt pathways, 
direct development of absorptive and secretory cell lineages from cycling progenitors in the intestinal epithelium. While the zebrafish intestine possesses mucin-producing goblet cells and regulatory enteroendocrine cells, they appear to lack immune-modulatory Paneth and tuft cells. At present, our understanding of absorptive lineages is less complete. Similar to mammals, the fish intestinal epithelium includes regionally specialized enterocytes that harvest nutrients from the lumen (Lickwar et al., 2017; Ng et al., 2005; Park et al., 2019; Wallace et al., 2005; Wang et al., 2010b). However, the extent of functional heterogeneity within enterocyte populations is unclear, and we do not know if the intestinal epithelium houses specialized absorptive cells such as antigen-capturing $\mathrm{M}$ cells, or recently described Best4/Otop2 cells (Parikh et al., 2019; Smillie et al., 2019). Likewise, despite experimental evidence for the existence of cycling progenitors (Crosnier et al., 2005; Rawls et al., 2004; Wallace et al., 2005), we lack expression markers that permit identification and manipulation of this essential cell type. Combined, these deficits have hampered our ability to harness the full potential of the zebrafish as a model of intestinal biology and host-microbe interactions.

From a microbial perspective, similarities between fish and mammals are also quite evident. For example, fish also rely on a complex network of germline-encoded innate defenses, and lymphocytebased adaptive defenses that prevent invasion of interstitial tissues by gut-resident microbes (Flores et al., 2020). Transcriptional studies showed that orthologous genes mediate microbe-dependent control of epithelial proliferation, nutrient metabolism, xenobiotic metabolism, and innate immunity (Hooper et al., 2001; Koch et al., 2018; Rawls et al., 2004; Reikvam et al., 2011). In vivo studies support a shared role for the microbiota in developmental processes including epithelial renewal, secretory cell differentiation, and gut motility (Cheesman et al., 2011; Troll et al., 2018; Wiles et al., 2016). Microbes also educate immune systems in fish and mammals, inducing control of mucosal inflammation and myeloid cell recruitment through Myd88-dependent TLR signals (Galindo-Villegas et al., 2012; Koch et al., 2018; Takeda and Akira, 2005). Like mammals, fish neutralize pathogenic bacteria via epithelial production of reactive oxygen 
species and antimicrobial peptides (Flores et al., 2010; Katzenback, 2015). Additionally, experimental evidence in fish revealed that epithelial alkaline phosphatase can detoxify LPS, a finding later corroborated in a mouse model (Bates et al., 2007; Goldberg et al., 2008). These findings demonstrate that zebrafish, alongside other models, can inform our understanding of microbial impacts on host development and disease.

While recent studies provided significant insights into microbe-dependent host processes, most of this work focused on how microbes impact whole organisms, the entire intestine, or intestinal regions. Thus, a large knowledge gap exists in our understanding of cell type-specific processes that rely on microbial signals. A few studies addressed this disparity via FACS sorting of intestinal epithelial subpopulations (Arora et al., 2018), however this method requires foreknowledge of, and access to, cell typespecific antibodies or reporters, and assays are limited to one cell type per experiment.

To achieve unbiased cell type-specific analysis of microbe-dependent processes, and to overcome limited cell characterization of the fish intestine, we prepared a single cell transcriptional atlas of intestines, and associated tissue, from six-day post-fertilization zebrafish larvae raised in a conventional environment, or in the absence of a microbiome. In conventional fish, we identified nineteen distinct cell types in the gut and associated tissue, several of which were previously undescribed. We completed a high-resolution map of cellular responses to the microbiota that showed cell-specific microbial impacts on growth, patterning, and immunity in the host. In summary, our work resolves the cellular composition of the zebrafish intestine and defines cell-specific host transcriptional networks regulated by the microbiota. 


\section{RESULTS}

\section{A single cell atlas of the larval intestine and associated tissue}

To trace the effects of commensal microbes on intestinal physiology, we prepared single-cell transcriptional profiles of gastrointestinal tracts, and associated tissue, from zebrafish larvae raised under conventional (CV) or germ-free (GF) conditions for six days after fertilization (Figure $1 \mathrm{~A}$ and Supplementary Figure 1). After filtering for dead cells and doublets, we determined gene expression profiles for 3,521 individual cells (1,939 GF; 1,582 CV). From binomial distribution analysis, we estimate that we captured cell types present at greater than $1 \%$ abundance, allowing us to identify most cell populations in the dissected samples.

To fill gaps in our understanding of intestinal cellular composition, we used a graph-based clustering approach to identify distinct cell types in the guts and associated tissues of CV larvae. We identified eighteen clusters of endodermal or mesodermal origin, and assigned identities based on expression of established fish or mammalian markers (Figure 1B). Within the intestinal epithelium, we identified secretory cells marked by expression of genes required for production and release of peptide hormones

(Figure 1D, Supplementary Figure 2), and enterocyte lineages enriched for expression of genes that control nutrient absorption and metabolism (Figure 1D-E). Apart from differentiated absorptive and secretory cells, we discovered a separate population that expressed classical markers of vertebrate intestinal progenitor cells, such as Notch pathway components ascl1a, atoh $1 b$, dld and her2, the zebrafish HES5 orthologue (Supplementary Figure 3), as well as gene products required for cell division (Figure 1DE). Pseudotime analysis placed Notch-positive, cycling cells at the root of all developmental trajectories

(Figure 1C) and identified transition markers for differentiation of all secretory and absorptive fates (Supplementary Figure 4). Thus, although lineage tracing studies are required for absolute confirmation, our trajectory and transcriptional data suggest we have identified markers for the zebrafish intestinal 
progenitor cell population. Consistent with this hypothesis, we note that progenitor-like cells expressed Sox family transcription factors that control cell fate specification (Figure 1E, Supplementary Figure 6).

In addition to intestinal epithelial lineages, we uncovered extra-intestinal clusters of mesenchymal, vascular, myeloid, acinar, and hepatic cells (Figure 1B and Supplementary Figure 5). While hepatocytes and acinar cells were characterized by metabolic regulation, mesenchymal tissue was characterized by expression of genes required to control growth and differentiation (Supplementary Figure 5), particularly genes associated with Wnt and BMP pathways (Supplementary Figure 6). As mesenchymal Wnt and BMP controls intestinal epithelial growth and differentiation in mammals (Vanuytsel et al., 2013), our data raise the possibility that similar intercellular interactions influence growth in the developing zebrafish gut. Finally, we found that vascular and myeloid cells were marked by expression of genes that control vasculogenesis, and immune cell activation and migration, respectively (Supplementary Figure 5).

In sum, we have unambiguously identified a panel of expression markers that distinguish all major intestinal lineages, including previously undescribed candidate progenitor cells. 
bioRxiv preprint doi: https://doi.org/10.1101/2020.11.06.371609; this version posted November 7, 2020. The copyright holder for this preprint (which was not certified by peer review) is the author/funder, who has granted bioRxiv a license to display the preprint in perpetuity. It is made available under aCC-BY 4.0 International license.

A

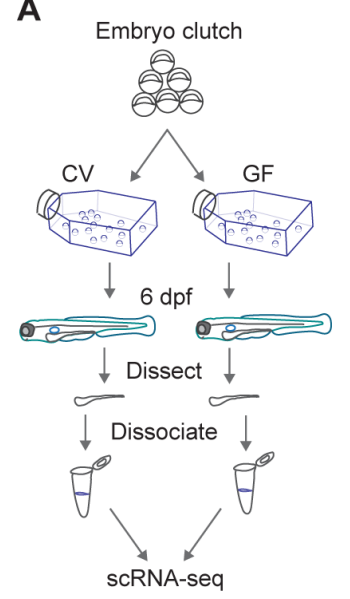

D

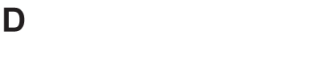

translation elial cell differentiation regulation of cell cycle cellular developmental procestion synaptic vesicle priming
sesponse to calcium ion response to calcium ion modulation of synaptic transmission modulation of synaptic transmission secretion by cel
electron transport chain
translation
chordate embryonic development electron transport chain
translation
chordate embryonic development cellular amide metabolic process chitin metabolic process generation of precursor metabolites and energ rentic metabolic process biosynthetic process aerobic respiration translation peptide biosynthetic process
generation of precursor metabolites and energy precursor metabolites and energy chitin metabolic process cellular detoxification cellular detoxification lipid transport
carbohydrate metabolic process peptide catabolic process anion transport
peptide catabolic transmembrane transport ion transport chitin metabolic proces response to vitami JAK-STAT cascad organic substance catabolic process
pyruvate transport
cellular respiration organic substance catabolic process
pyruvate transport
cellular respiration regulation of actin filament polymerization response to oxidative stress protein catabolic process
ponse to oxidative stress protein catabolic process
wound healing cell junction assembly cell junction assembly
endocytosis actin filament-based process response to stimulus tissue regeneration protein folding signal transduction anatomical structure developmen
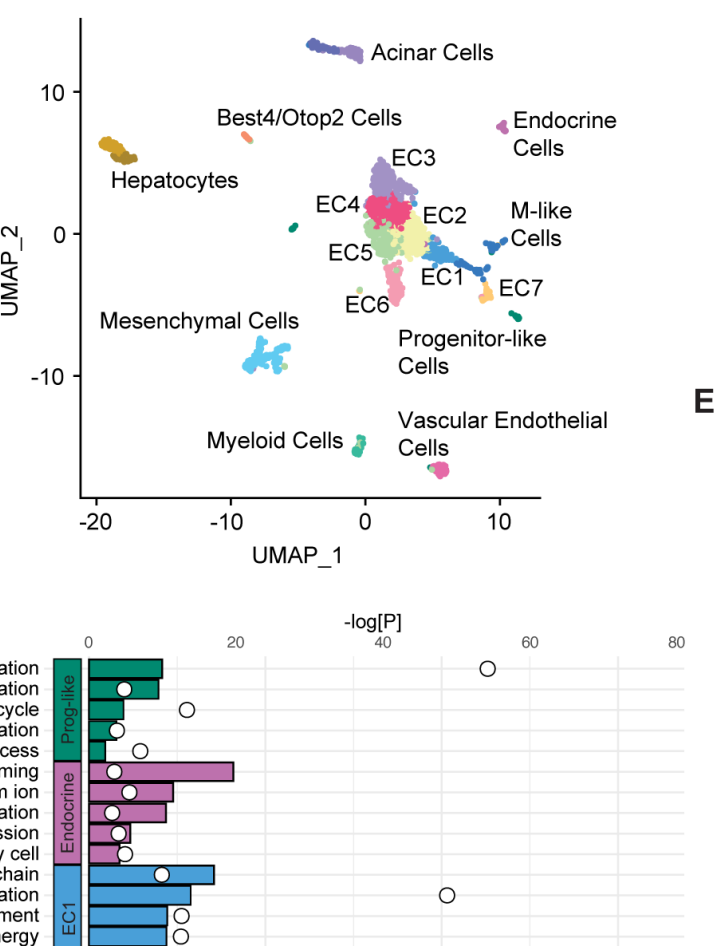

O
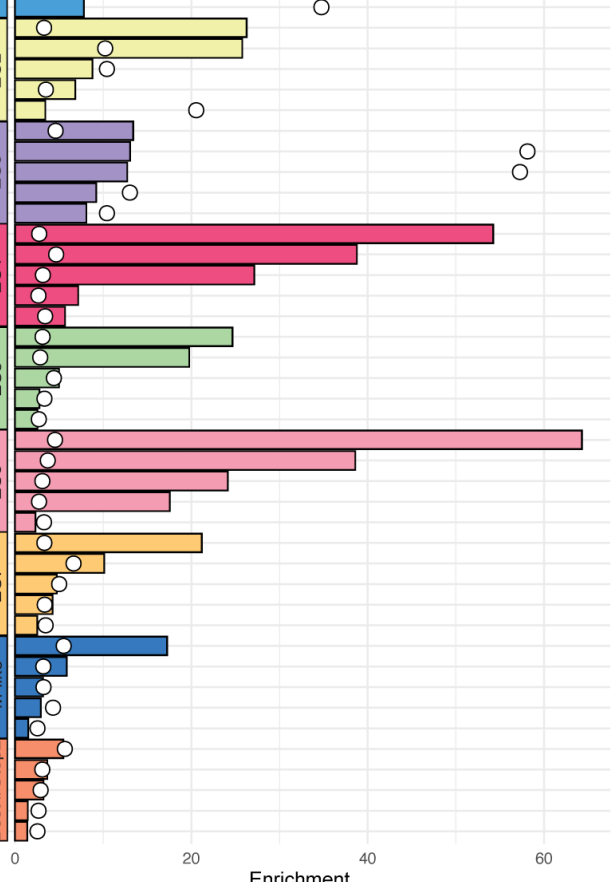

C

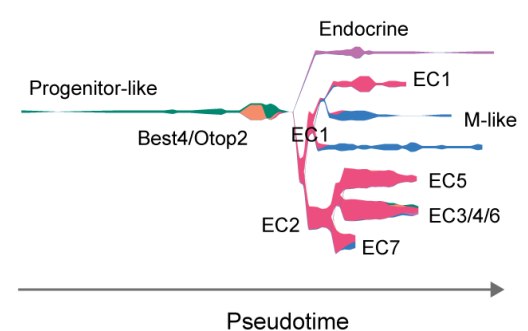

E

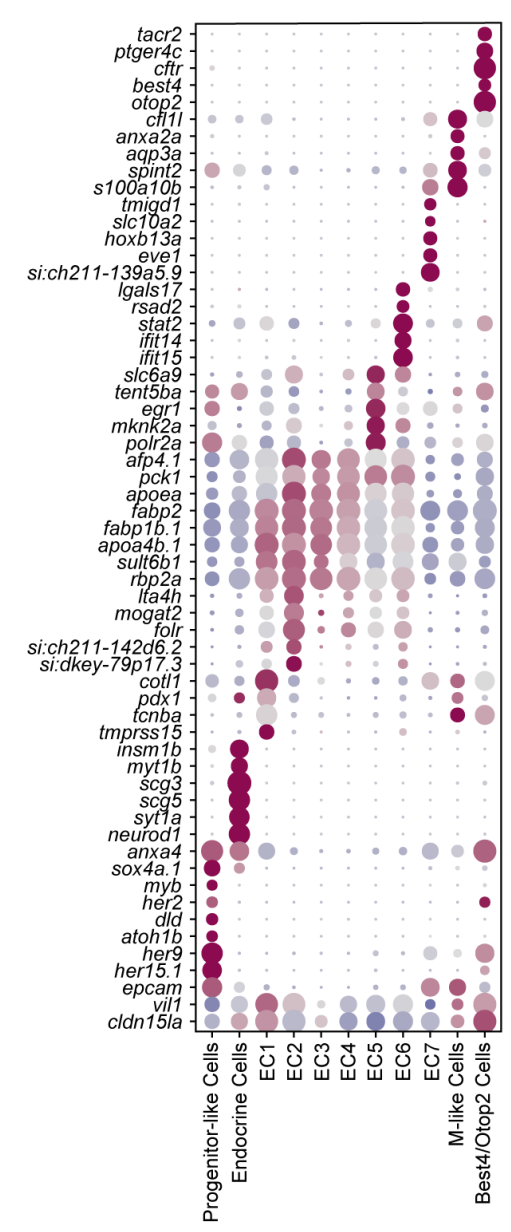

Relative Expression

Percent Expressed

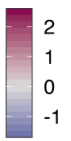

0

- 25

- 50

75
100

Figure 1. The zebrafish intestinal epithelium contains transcriptionally distinct cell populations. $(A)$ Experimental design for transcriptional profiling of single cells in the zebrafish intestine. (B) UMAP plot visualizing cell types of conventional fish intestines $(n=25)$ based on marker gene expression. Cells are color coded by cell type. $(C)$ Single-cell trajectory reconstruction of epithelial lineages. $(D)$ Gene ontology (GO) enrichment analysis of epithelial cell types based on genetic markers. Top 5 non-redundant GO terms are shown. Enrichment score is represented by bar length and P-value is indicated with white circles. $(E)$ 
Heatmap of cluster markers colored by relative gene expression. The size of the dot indicates proportion of expressing cells per cell type.

\section{Heterogeneity of absorptive lineages within the intestinal epithelium.}

Like most animals, the zebrafish intestinal epithelium is dominated by regionally-specialized subtypes of absorptive cells required for acquisition and transport of material from the gut lumen (Lickwar et al., 2017; Ng et al., 2005; Park et al., 2019; Wallace et al., 2005; Wang et al., 2010b). To uncover the heterogeneity of absorptive cell types within the zebrafish gut, we examined CV larvae for gene expression patterns that indicated regionally or functionally specialized absorptive cells.

$86 \%$ of all CV intestinal epithelial cells were enterocytes that we stratified into seven groups based on distinct gene expression signatures (Figure 2A). Individual clusters frequently had gene expression signatures consistent with localization to defined regions of the intestinal epithelium (Lickwar et al., 2017; Wang et al., 2010b). For example, clusters one to three were functionally related and expressed genes involved in energy metabolism (Figure 2B), as well as positional markers such as ada and fabp2 that indicate anterior localization (Figure 2D). Cluster four was the dominant enterocyte type that accounted for $21 \%$ of all enterocytes, and also expressed markers consistent with anterior localization (Figure 2D). Functionally, cluster four cells were metabolically active, expressing genes required to process carbohydrates, lipoproteins and chitin (Figure 2B). Cluster five cells were dedicated to ion transport and peptide catabolism (Figure 2B), and positional marker expression patterns revealed reduced expression of anterior markers alongside upregulation of middle and posterior markers relative to ECs 1-4 (Figure 2D), suggestive of middle to posterior intestinal localization. In contrast, cells from cluster seven were highly enriched for middle intestinal markers such as slc10a2 and tmigd1 (Figure 2D), and expressed gene products involved in oxidative stress responses (Figure 2B) indicating separate roles for putative distal EC clusters five and seven in ion absorption, or metabolite detoxification. Finally, we uncovered an 
enterocyte type - cluster six - that appeared predominantly anteriorly localized (Figure 2D) and was highly enriched for expression of gene products that transduce interferon pathway signals (Figure 2B), suggesting the zebrafish epithelium contains specialist enterocytes dedicated to interferon-based regulation of gut function.

In addition to conventional enterocytes, we found that the intestinal epithelium contained three additional absorptive cell types, two of which have not yet been described in fish. First, we manually searched our dataset for lysosome-rich enterocytes (LREs), which are protein-capturing enterocytes of the posterior middle intestine recently described in zebrafish (Park et al., 2019). We identified a small subset, originally clustered with EC7, that expressed LRE marker genes and was enriched for small molecule metabolism and transport (Figure 2C-D, Supplementary Figure 7A). Separately, our initial clustering analysis revealed that the zebrafish intestine contains a distinct population of Best4/Otop2 cells (Figures 1B-E, 2C), a posterior (Figure 2D), absorptive cell type only recently described in humans (Parikh et al., 2019; Smillie et al., 2019), and unknown in zebrafish. Zebrafish Best4/Otop2 cells were enriched for factors involved in actin filament organization, as well as signal transduction and neutrophil migration (Figure 2C), indicating that Best4/Otop2 cells may have innate immune functions. As in mammals, zebrafish Best4/Otop2 cells were also enriched for Notch-responsive genes of the hes-related family (Supplementary Figure 3B). Finally, we identified an epithelial cell type with developmental and functional similarities to vertebrate $\mathrm{M}$ cells (Figures 1B-E, 2C). Like mammalian M cells, zebrafish M-like cells shared a developmental trajectory with absorptive enterocytes (Figure 1C) but did not express markers of enterocyte metabolism (Figure 2C). Instead, M-like cells expressed claudins, annexins, and endocytosis regulators (Figure $2 \mathrm{C}$ and Supplementary Figure 7B), classical $\mathrm{M}$ cell markers that are essential for microbial transcytosis from the gut lumen to the host interior. Notably, progenitor-like cells highly expressed tnfrsf11a (Supplementary Figures 3B and 7B-C), the RANKL receptor required for $M$ cell differentiation in mammals (Knoop et al., 2009), supporting the idea that, similar to mammals, zebrafish 
M-like cells differentiate from multi-potent progenitors. In situ hybridization against M-like cell marker icn

(Figure 2E) revealed transcript enrichment in the posterior-most intestinal region (Figure 2F), suggesting that zebrafish $\mathrm{M}$-like cells reside in the region analogous to the mammalian colon.

In summary, the larval intestine houses a community of specialist cells that display a previously underappreciated degree of similarity to mammalian intestines, including mesenchymal sources for growthregulatory pathways; cycling cells capable of generating the intestinal epithelium; and regionallyspecialized absorptive cells that capture bulk material from the lumen. 
bioRxiv preprint doi: https://doi.org/10.1101/2020.11.06.371609; this version posted November 7, 2020. The copyright holder for this preprint (which was not certified by peer review) is the author/funder, who has granted bioRxiv a license to display the preprint in perpetuity. It is made available under aCC-BY 4.0 International license.

A

EC1

EC2

EC3

EC4

EC5

EC6 EC7
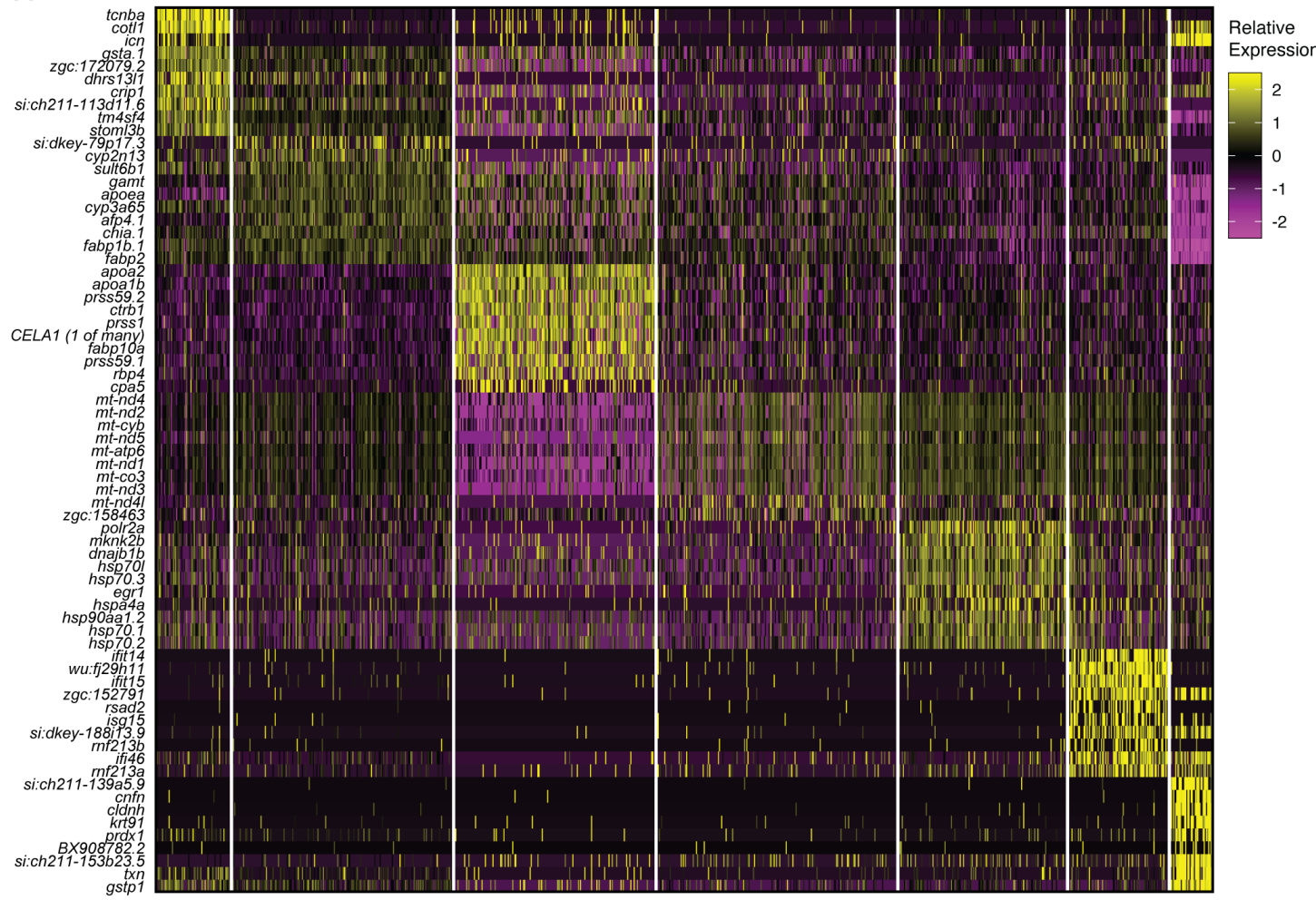

B

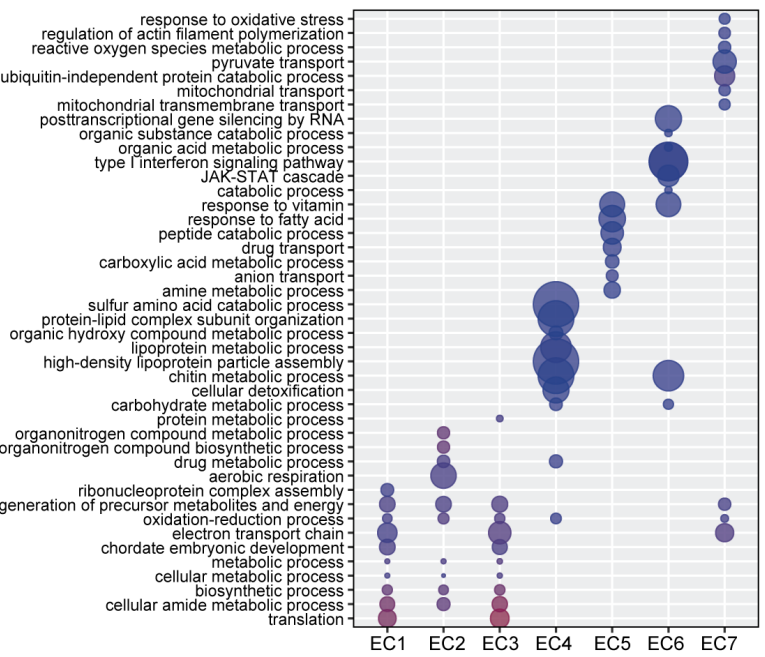

C

D
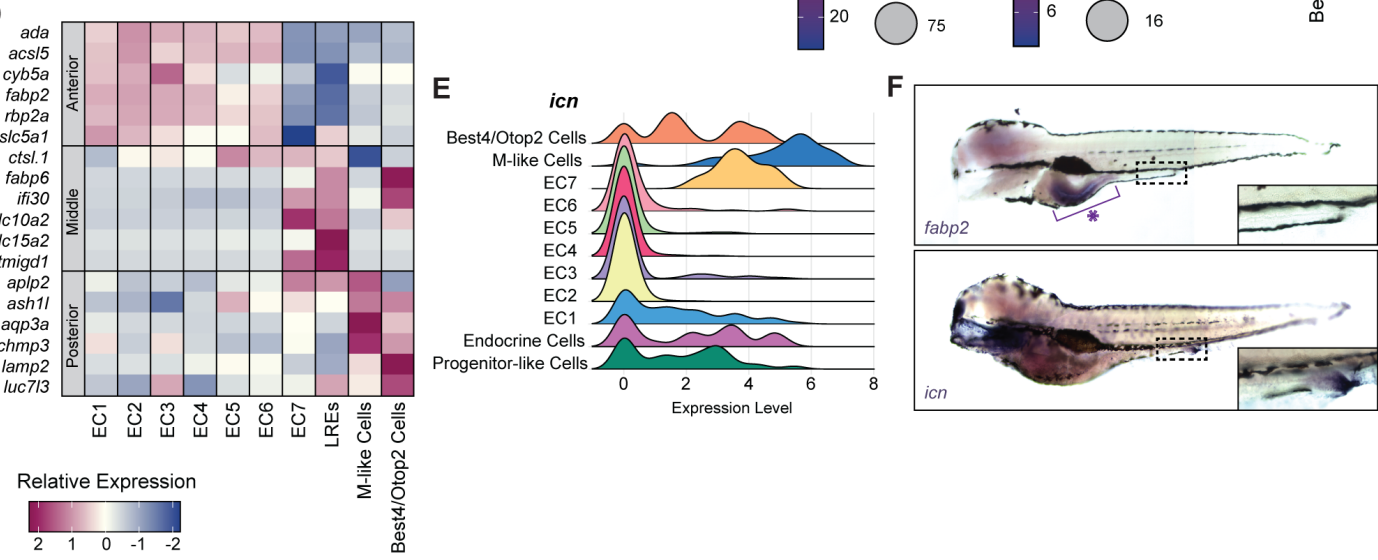

กั้

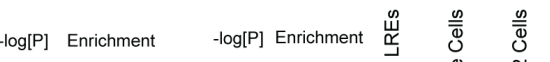

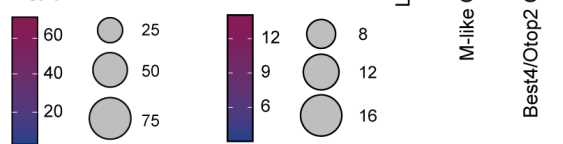


Figure 2. Absorptive cells are regionally and functionally specialized. $(A)$ Canonical enterocyte gene signatures, where color indicates relative expression per cell, and cells are grouped according to cell type. $(B-C) \mathrm{GO}$ enrichment analysis for canonical enterocytes (B) and additional absorptive cell types (C), where enrichment score is indicated by dot size and $P$ value is represented by color. $(D)$ Heatmap showing relative expression of established regional marker genes in each absorptive cell type. $(E)$ Ridge plot showing log normalized expression of ictacalcin (icn) per epithelial cell type. $(F)$ In situ hybridization of fabp2 (fatty acid binding protein 2) and icn. fabp2 transcripts are enriched in the anterior intestine (asterisk) and icn transcripts are enriched in the caudal intestine (shown in inset).

\section{Germ-free growth disrupts gene expression throughout the intestine and associated tissue.}

Microbial factors direct development, differentiation, and function of host tissues. However, cellspecific microbe responses have been difficult to chart to date. To assess microbe-responsive genes at the cellular level, we initially confirmed microbial effects on expression of 24 previously identified microberesponsive genes (Rawls et al., 2004) and expanded these findings to show that many of the effects occur in subsets of host cells (Supplementary Figure 8). For example, expression of moesin a, involved in blood vessel development (Wang et al., 2010a), was specifically downregulated in vascular endothelial cells of GF fish. Next, we used our transcriptional data to resolve impacts of GF growth on all cell lineages described in this study. First, we mapped intestinal organization in GF larvae. Similar to CV counterparts, GF intestinal epithelia possessed Notch-positive progenitor-like cells, secretory endocrine cells, and absorptive enterocytes, including an LRE cluster detected through unsupervised clustering (Figure 3A). Intestinal epithelial cells had broadly similar gene expression signatures and functional markers in CV and GF fish. For example, in both groups, progenitors expressed markers of growth and differentiation; endocrine cells expressed genes required for secretion of regulatory hormones; and enterocytes were defined by gene expression patterns consistent with nutrient capture and digestion (Figure 3B and Supplementary Figure 9A and 9B). Pseudotime analysis confirmed that progenitor-like cells generated all other epithelial types (Supplementary Figure 9D), and positional marker expression patterns pointed to defined rostro-caudal localizations for the respective lineages (Supplementary Figure 9C). Additionally, 
extra-intestinal tissue of GF fish contained mesenchymal cells, acinar cells, hepatocytes, and myeloid cells dedicated to morphogenesis, metabolism, and immunity, among other processes (Supplementary Figure 9E and 9F). Thus, at a superficial level, intestines of CV and GF larvae appear similar in cellular anatomy, arrangement, and biological function.

However, examination of individual cell types, or biological pathways, uncovered pronounced effects of microbiome removal. First, we found that GF growth resulted in substantial shifts in cell type representation (Figure 3C). Relative to CV larvae, GF larvae had elevated numbers of absorptive cells, fewer mesenchymal and progenitor-like cells, and a substantial depletion of cells that expressed vascular or myeloid markers. Among enterocytes, we detected a complete loss of enterocyte cluster six cells that express interferon pathway components (Figure 3A and 3C). For example, ifit14 and ifit15, orthologous to human IFIT1 and IFIT2, were either lowly expressed or absent from GF epithelia (Figure 3B and Supplementary Figure 10). Significant loss of CV marker genes was also detected in the progenitor-like cell compartment, where secretory cell differentiation factors $d l d$, atoh $1 b$, and myb were largely absent from her positive progenitor-like cells, instead appearing at low levels in Best4/Otop2 cells (Figure 3B).

Our observation that GF intestines were defective in development of EC6, an immune-dedicated EC type, prompted us to assess immune response pathways in GF relative to CV intestines. For these studies, we examined the consequence of GF growth for expression of a representative set of microbial sensors, NF-kB pathway components, cytokines and chemokines. Upon integration of CV and GF datasets, we observed striking changes to germline-encoded immune response pathways. In CV larvae, we detected cell-restricted expression of key immune sensors and effectors (Figure 3D). For example, myeloid cells expressed immune-regulatory cytokines such as $c x c / 8 a, i l 1 b, i l 17 a / f 3$, tnfa, and tnfb, whereas the vasculature was characterized by enriched expression of microbial sensors such as t/r4ba and nod1, and the inflammation regulator ahr2. Similar to mammals, hepatocytes of CV larvae expressed the hamp antimicrobial peptide, while mesenchymal cells were characterized by enriched expression of NF-kB 
pathway members, the $c x c / 8 b$ and $c x c / 12$ chemokines, and the $\operatorname{tg} f b 1 a$, $\operatorname{tg} f b 2$ and $\operatorname{tg} f b 3$ cytokines. Within the intestine, most enterocyte subtypes produced alpi2, a phosphatase required for detoxification of bacterial lipopolysaccharide, whereas endocrine cells expressed il22, an inflammatory cytokine that activates innate defenses in epithelial cells (Dudakov et al., 2015). Consistent with previous reports (Kanther et al., 2011), saa was expressed in mid-intestinal enterocyte population EC7, and we also observed enhanced nod2 peptidoglycan sensor expression in CV progenitor cells, similar to mice (Nigro et al., 2014). Removal of the microbiome significantly impacted organization of immune pathways in developing larvae. In particular, we noted a near complete loss of il17a/f3 and cxc/19 expression from myeloid tissue; il22 from endocrine and vascular endothelial cells; nod2 from progenitors; and greatly diminished expression of tgf isoforms in EC5, Best4/Otop2 cells, and mesenchymal cells. Combined, our data demonstrate a sophisticated partitioning of immune gene expression patterns across larval cell types, many of which indicate shared microbe-response pathways in zebrafish and mammals and show that growth of zebrafish larvae in the absence of a conventional microbiome disrupts immune processes throughout the host. 
A

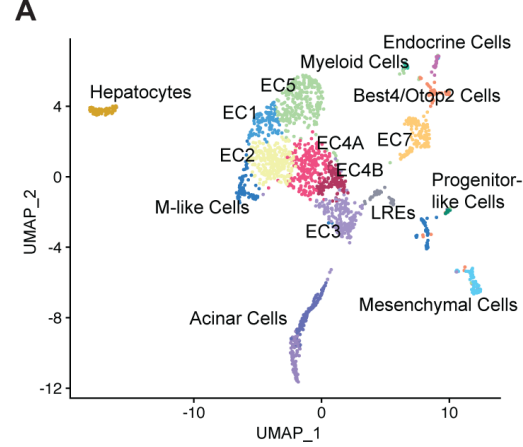

C

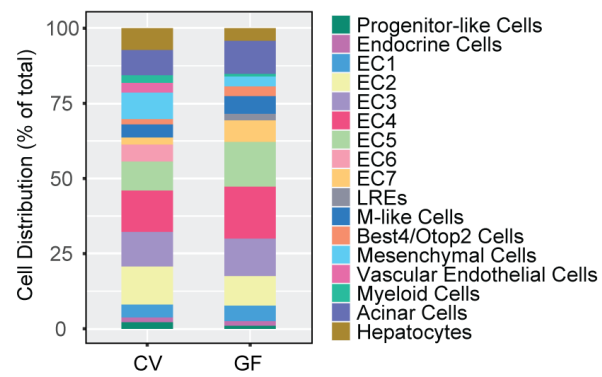

B

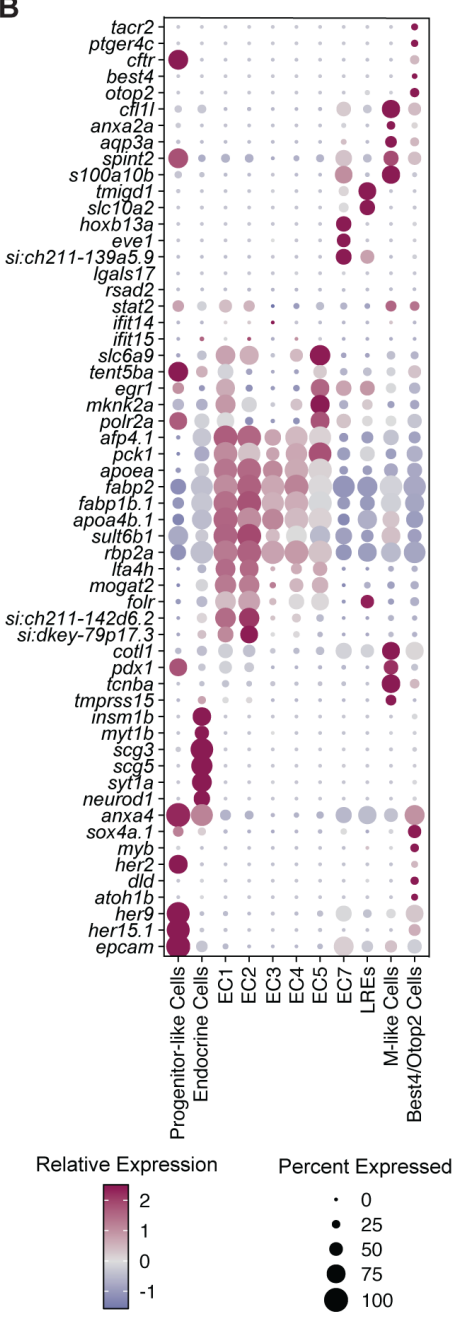

D

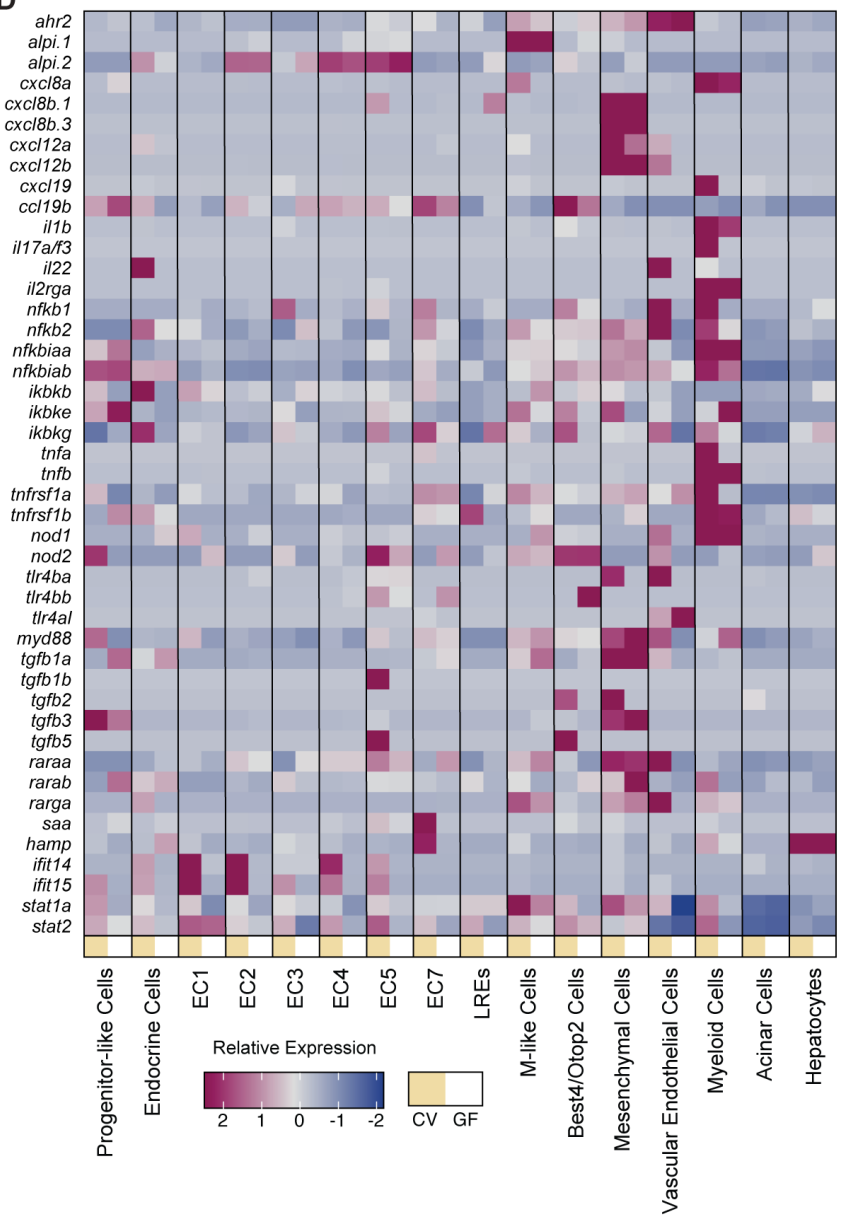

Figure 3. Germ-free fish exhibit shifts in cellular composition and transcriptional profiles. (A) UMAP plot showing cell types of GF fish intestines $(n=25)$ based on marker gene expression and color coded based on cell type. (B) Heatmap of $\mathrm{CV}$ epithelial cell population gene markers as expressed in GF epithelial cell populations, colored by relative gene expression. The size of the dot indicates proportion of expressing cells per cell type. (C) Proportional representation of cell types per CV or GF intestinal atlases. (D) Heatmap showing relative expression of genes with known immune function in CV and GF intestinal cell populations. 


\section{Cell-specific patterns of host responses to the microbiome.}

Our analysis of microbe-regulated immune activity, and microbe-responsive marker gene expression patterns indicated cell-specific responses to a conventional microbiome. Consistent with a hypothesis that each cell type responds differently to microbial elimination, we found that GF growth caused substantial changes to host gene expression in enterocytes (Figure 4A) but had minimal effect on acinar cells (Figure 4B). Specifically, we identified plac8.1, whose mouse homologue is required to temper inflammation in response to microbes (Ledford et al., 2007), as the most downregulated gene in the collective enterocyte population (Figure 4A). Comparatively, apoc1 and apoa2, lipoprotein components, were only moderately downregulated in acinar cells (Figure 4B). Within the progenitor-like compartment, removal of the microbiota resulted in diminished expression of mitotic factors, and elevated expression of genes required for cell-cell adhesion (Figure 4C, E), consistent with growth-promoting roles for the microbiome (Cheesman et al., 2011). Endocrine cells adjusted to removal of the microbiome with diminished expression of genes that control processing and transport of peptide hormones (Figure 4C, F), and a significant drop in ins expression (Figure 4F). Across the enterocyte subtypes, we detected gene expression shifts that indicate diminished lipid transport and metabolism, greatly enhanced peptide metabolism, and reduced innate immune activity (Figure 4C, D), further supporting requirements of the microbiome to promote lipid metabolism (Sonnenburg and Bäckhed, 2016). We uncovered similarly pronounced effects of the microbiome on gene expression in extra-intestinal tissue. In particular, we noted suppression of immune activity in myeloid cells raised without a microbiome, shifts in developmental regulatory processes among mesenchymal cells, and metabolic adaptation in hepatocytes (Figure 4G). Combined, our data show that growth of a developing larva in the absence of a microbiome changes the composition and transcriptional activity of all intestinal cells examined in this study. 
bioRxiv preprint doi: https://doi.org/10.1101/2020.11.06.371609; this version posted November 7, 2020. The copyright holder for this preprint (which was not certified by peer review) is the author/funder, who has granted bioRxiv a license to display the preprint in perpetuity. It is made available under aCC-BY 4.0 International license.

A

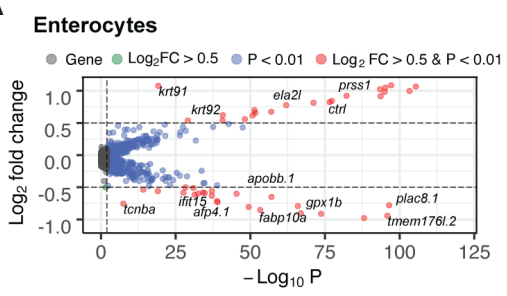

B

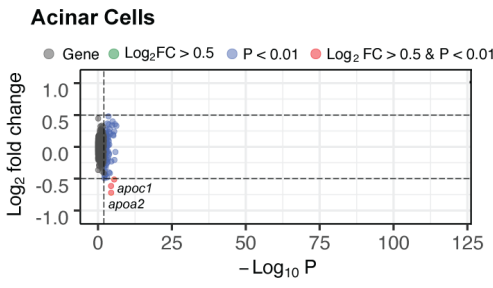

D

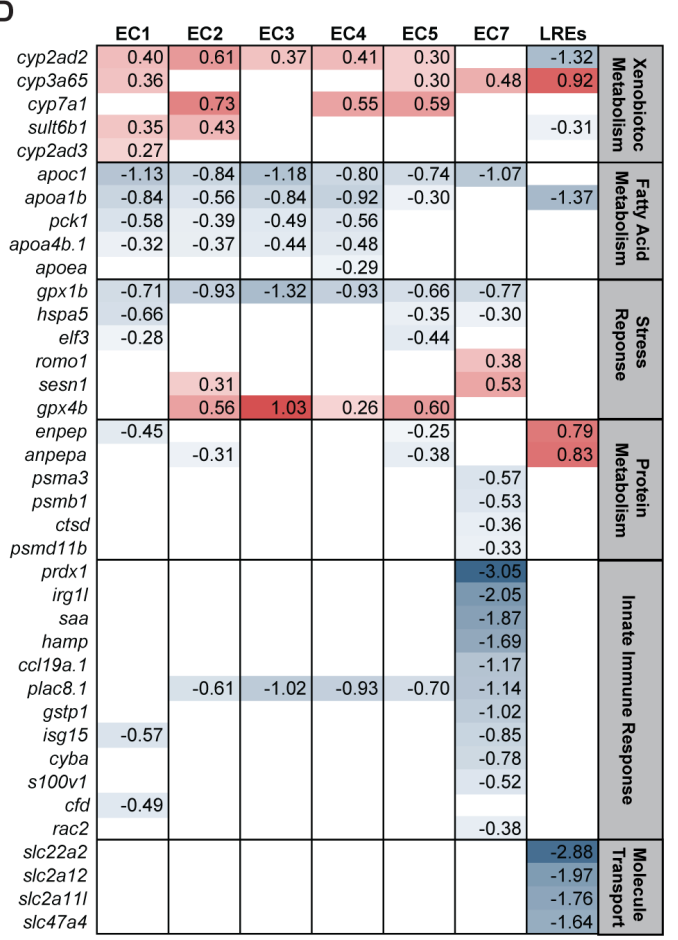

E Progenitor-like Cells

Metabolic Process Cell Cycle Regulation

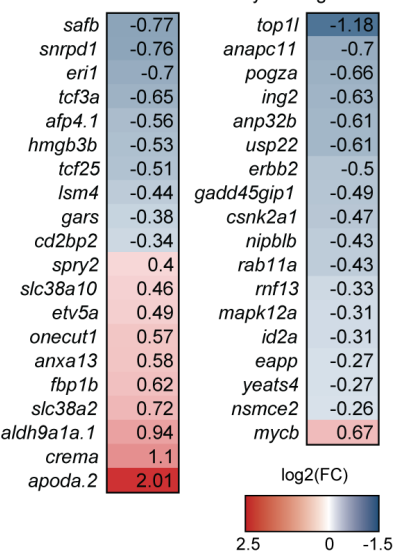

C Transport cadpsa -0.53 \begin{tabular}{r|r} 
ist1 & -0.53 \\
amph & -0.52
\end{tabular} amph -0.52 dnm2a $\quad-0.48$ vamp2 -0.41

$r a b 3 d b \quad-0.37$

rab1ba $\quad-0.35$ chmp6b -0.34 trappc5 -0.33

Peptide Hormone Metabolism

\begin{tabular}{r|r|} 
ins & -6.14 \\
scg $2 b$ & -0.94 \\
$c p e$ & -0.62 \\
insl5a & -0.57 \\
pcsk1 & -0.43 \\
pcsk2 & -0.41 \\
\cline { 2 - 2 }
\end{tabular}

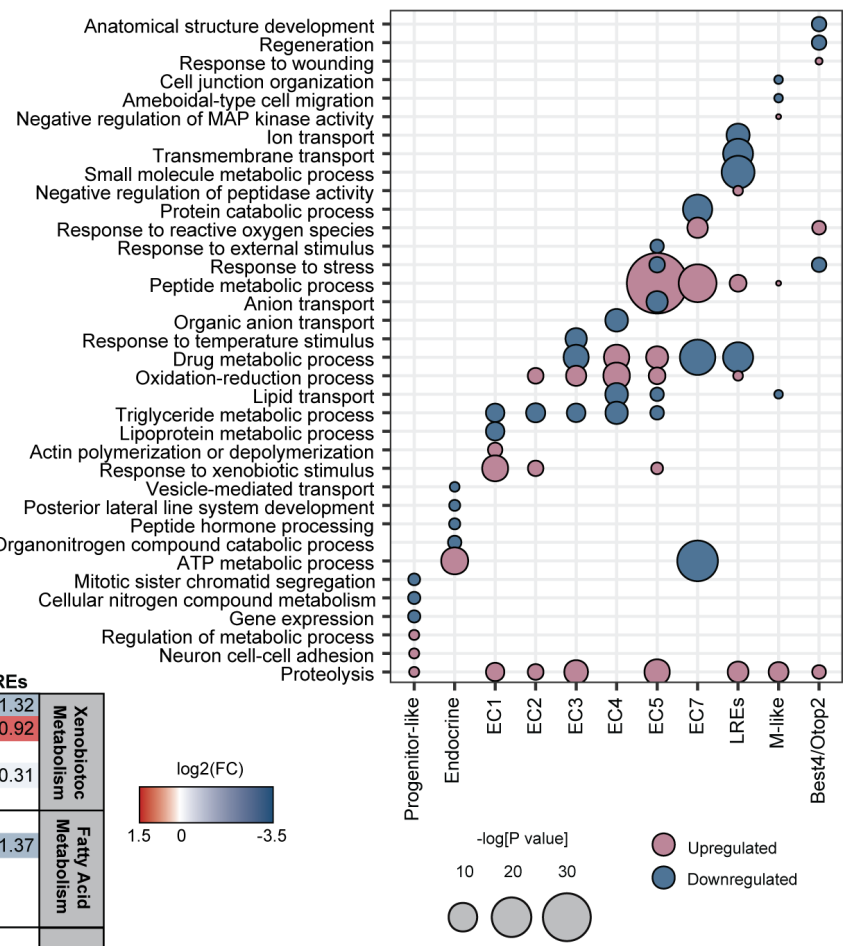

G

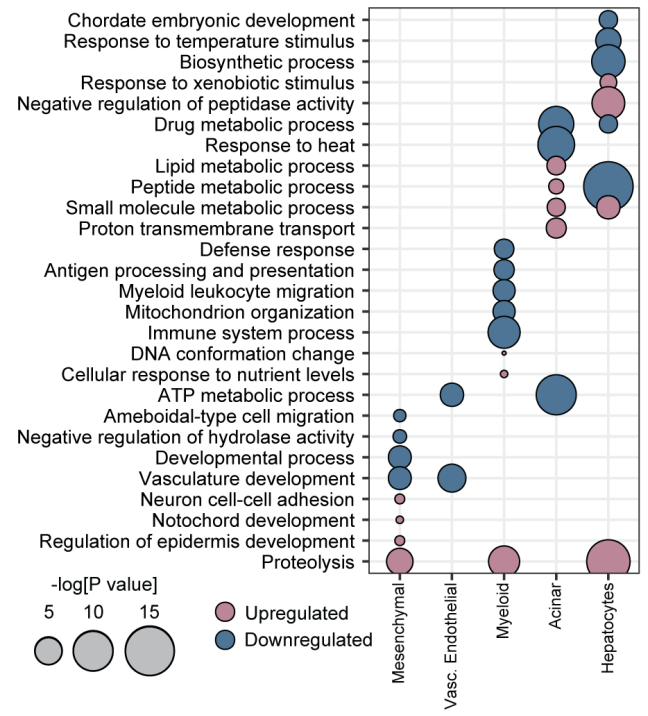

Chordate embryonic development Drug metabolic process Response to heat Peptide metabolic process all molecule metabolic process

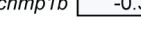


Figure 4. The microbiota stimulates specialized processes in every intestinal cell type. $(A-B)$ Volcano plots showing differentially expressed genes in GF relative to CV enterocytes (A) or acinar cells (B), color coded according to significance and $\log _{2} F C$. $(C, G) G O$ enrichment analysis of differentially regulated processes in GF relative to CV epithelial cell types (C) or extra-intestinal cell types (G). Significance of the change is indicated by dot size and direction of the change is represented by color. $(D)$ Gene expression changes in enterocyte cell populations of GF relative to CV fish, broken down by cellular process. $(E)$ Metabolic and cell cycle gene expression changes in GF relative to CV progenitor-like cells. $(F)$ Changes to endocrine cell expression of genes involved in vesicle-mediated transport and peptide hormone metabolism in GF relative to CV fish.

\section{The microbiome is essential for intestinal vascularization.}

We discovered a pronounced loss of cells that expressed vasculature markers, and diminished expression of key vasculature developmental regulators in multiple cell types of GF larvae relative to CV controls (Figure 3C, 4G, 5A). For example, larvae raised in GF conditions expressed lower amounts of proangiogenic transcription factors such as foxf1 and fli1a. Likewise, we detected significant drops in expression of Vascular Endothelial Growth Factor (VEGF)-type receptor tyrosine kinases, such as flt1 and the VEGFR2 ortholog, $k d r$, a prominent vasculogenesis inducer (Covassin et al., 2006) (Figure 5A). Combined, these data raise the possibility that GF growth has detrimental consequences for formation of gut-associated vascular tissue. In larvae, intestinal vasculogenesis commences approximately three days after fertilization (Isogai et al., 2001) a time that matches microbial colonization of the lumen. At this stage, a population of angioblasts migrates ventrally from the posterior cardinal vein, establishing the supra-intestinal artery, and a vascular plexus that gradually resolves into a parallel series of vertical vessels and the sub-intestinal vein (Goi and Childs, 2016; Lenard et al., 2015; Nicenboim et al., 2015) (Figure 5B). The gut vasculature delivers nutrients from the intestine to the hepatic portal vein, supporting larval growth and development. To determine if the microbiome affects intestinal vasculogenesis, we used $k d r l: m$ Cherry larvae to visualize the vasculature of fish that we raised in the presence, or absence of a conventional microbiome for six days (Figure 5B, C). We did not observe effects of the microbiome on formation or spacing of the supra-intestinal artery and the sub-intestinal vein, VEGF-independent 
developmental processes. In both groups, the artery and vein effectively delineated the dorsal and ventral margins of the intestine (Figure 5B, C). In contrast, removal of the microbiome had significant effects on development of connecting vessels, a VEGF-dependent event. Consistent with this, we observed a near $50 \%$ reduction of intestinal kdrl:mCherry signal in GF larvae compared to CV counterparts (Figure 5D). Thus, we conclude that microbial factors are essential for proper development of the zebrafish intestinal vasculature. 
A Vasc. Endothelial Cells

\begin{tabular}{r|r} 
Gene & $\log 2(\mathrm{FC})$ \\
\cline { 2 - 2 } clec14a & -2.28 \\
\cline { 2 - 2 } fli1a & -1.62 \\
\cline { 2 - 2 } notchl & -1.59 \\
\cline { 2 - 2 } aplnrb & -1.50 \\
she & -1.37 \\
flt1 & -1.19 \\
\cline { 2 - 2 } arhgef9b & -1.18 \\
sema4c & -1.16 \\
kdr & -0.98 \\
\cline { 2 - 2 } mcamb & -0.90
\end{tabular}

Mesenchymal Cells

Gene $\log 2(\mathrm{FC})$

$c x c / 12 a$

foxf1

angpt/4

sema3e

$\operatorname{tgfbr} 1 b$

uqcrb

mcamb

fgfr2

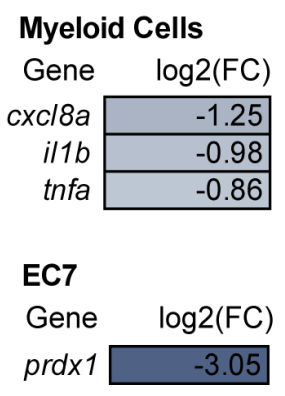

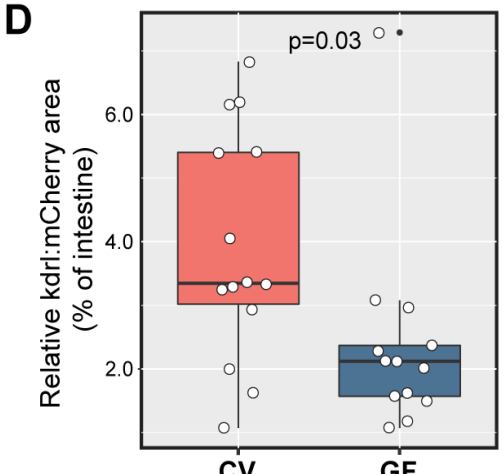

cV

GF
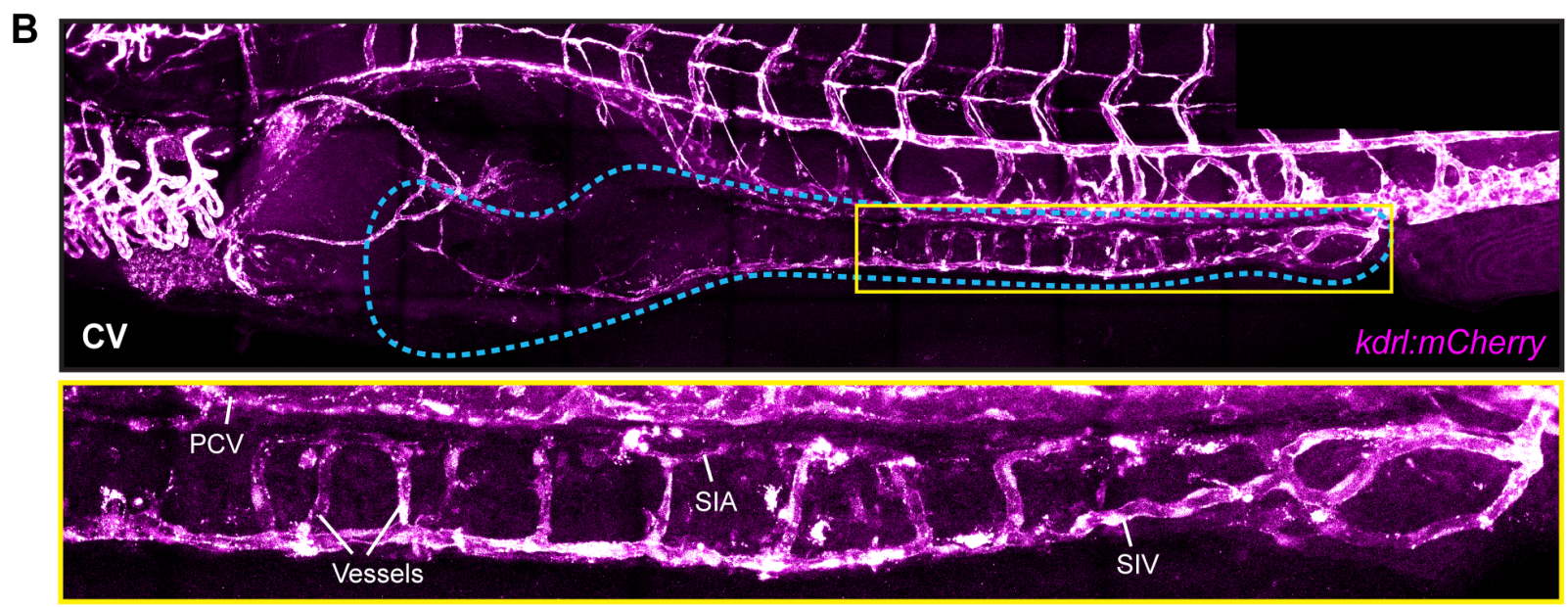

C
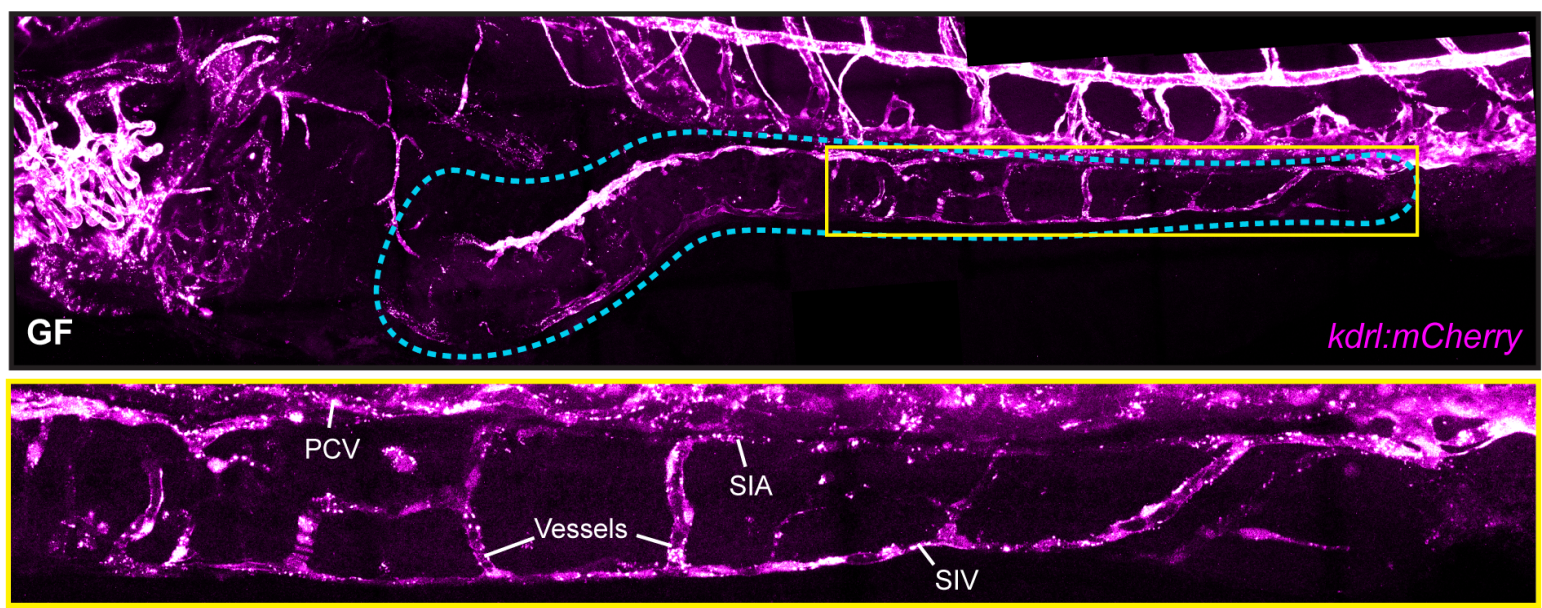

Figure 5. Microbes signal through multiple cell types to promote VEGF signaling and intestinal vasculogenesis. $(A)$ Downregulation of angiogenic factors in multiple intestinal cell types. $(B-C)$ Expression of $k d r l: m C h e r r y$ in zebrafish $6 \mathrm{dpf}$ raised under CV (B) or GF (C) conditions. Corresponding brightfield images were used to identify the intestine, outlined in blue. Bottom panels in B and C show enlarged region of middle to posterior intestine within yellow boxes of respective upper panels. PCV- posterior cardinal vein; SIA- supra-intestinal artery; SIV- sub-intestinal vein. $(D)$ Box and whisker plot showing the area of intestinal kdrl:mCherry signal relative to total intestinal area. $n=14$ and $n=13$ for CV and GF fish respectively. Significance was determined via Student's $t$ test. 


\section{DISCUSSION}

Gut microbial factors are critical determinants of animal development (Sekirov et al., 2010). Comparative studies with CV and GF larvae uncovered numerous microbial effects on the host, including impacts on proliferation, cell fate specification, and metabolism in the intestinal epithelium (Bates et al., 2006; Hooper et al., 2001; Rawls et al., 2004; Reikvam et al., 2011). Importantly, the molecular and genetic networks that determine intestinal development are highly similar between zebrafish and mammals (Davison et al., 2017; Lickwar et al., 2017). Thus, discoveries made with fish have the potential to reveal foundational aspects of host-microbe relationships. However, important knowledge gaps prevent us from maximizing the value of zebrafish-microbe interaction data. In particular, we know considerably less about the cellular composition of the zebrafish intestinal epithelium compared to mice and humans. For example, the zebrafish epithelium contains basal cycling cells that likely act as epithelial progenitors (Crosnier et al., 2005; Rawls et al., 2004; Wallace et al., 2005). However, we lack genetic markers that allow us to identify, or isolate, the progenitor population for experimental characterization. Likewise, it is unclear if the fish gut contains functionally heterogenous absorptive lineages, similar to the mammalian intestine. To bridge these deficits, and permit cell-by-cell definition of host responses to the microbiome, we prepared single-cell atlases of the larval intestine raised under conventional, or germ-free conditions. We identified nineteen distinct cell types in the gut, and associated tissue, several of which were unknown in fish. Comparisons between conventional and germ-free fish allowed us to delineate impacts of the microbiome on growth, patterning, immune, and metabolic processes in each cell type. We believe these findings constitute a valuable resource that will support efforts to understand how microbes control vertebrate physiology.

Looking at the intestinal epithelium, we identified cycling cells that express classical intestinal stem cell markers, such as the Delta-like ligand $d l d$, the Notch pathway components ascl1a and atoh $1 b$, and several hes-related transcription factor family members that respond to Notch. Notably, expression of cell 
cycle markers, and dld declined in this population in GF larvae, consistent with diminished epithelial growth in fish raised in the absence of a microbiome (Bates et al., 2006; Rawls et al., 2004). Our data align with related work in vertebrates and invertebrates (Buchon et al., 2009; Cheesman et al., 2011; Rawls et al., 2004; Reikvam et al., 2011), and argue that we have uncovered intestinal stem cell markers for zebrafish larvae. In mammals, Lgr5 is a classical intestinal stem cell marker, with roles in modification of Wnt-dependent signaling (Haegebarth and Clevers, 2009). Wnt is important for microbe-dependent intestinal epithelial growth in zebrafish. However, the zebrafish genome does not appear to encode an Igr5 ortholog. Instead, the fish genome encodes the related lgr4 and lgr6 genes (Hirose et al., 2011). We did not observe enriched expression of Igr4 or Igr6 in the fish gut, raising the possibility that Wnt-Lgr signaling is not essential for specification and growth of fish intestinal stem cells. In this regard, zebrafish may be more akin to Drosophila, where Wnt activity has ancillary roles in midgut intestinal stem cell growth (Lin et al., 2008). In the future, it will be of interest to perform clonal marking studies on fish progenitor-like cells to test their ability to generate a mature epithelium, and to resolve the roles of WntLgr activity in zebrafish epithelial homeostasis.

Separate to cycling, Notch-positive cells, we identified transcriptional markers for secretory enteroendocrine cells. As a caveat, we failed to identify mucin-producing goblet cells (Crosnier et al., 2005; Wallace et al., 2005) in either of our data sets, indicating a gap in our resolution of secretory lineages that merits addressing in follow-up studies. Comparisons between CV and GF fish revealed pronounced effects of the microbiome on secretory activity within the endocrine lineage. Most notably, we observed a precipitous drop in expression of the insulin ortholog, ins, supporting earlier work that established essential requirements for gut microbes to drive insulin production in larvae (Hill et al., 2016).

Upon examination of absorptive lineages, we identified transcriptional signatures of regionally and spatially specialized enterocytes in CV larvae, as well as an extensive profile of gene expression in lysosome-rich enterocytes that mediate protein absorption and metabolism (Park et al., 2019). Our 
findings provide a molecular underpinning of the regionally-controlled nature of nutrient metabolism in the zebrafish gut. Perhaps more intriguingly, we also uncovered two absorptive lineages that were unknown in the zebrafish gut. For example, we identified Best4/Otop2-positive enterocytes, a minimallycharacterized cell type only recently discovered in humans (Parikh et al., 2019; Smillie et al., 2019). Given the utility of zebrafish for examination of gut development, particularly in the context of host-microbe interactions, we believe fish will be of considerable value for in vivo characterization of Best4/Otop2 cells. In addition to metabolically active lineages, we identified a separate absorptive cell type that displays transcriptional and developmental similarities to mammalian $\mathrm{M}$ cells, a cell type dedicated to transcytosis of microbial antigens from the lumen to lymphoid tissue (Dillon and Lo, 2019). There is little data on M cells in zebrafish. However, M cells have been identified in salmonids (Fuglem et al., 2010), and our results match an earlier study that posited the existence of posterior M-like cells in the larval zebrafish gut (Løvmo et al., 2017). Thus, it will be of interest to functionally test the actions of putative zebrafish $M$ cells in the future, a strategy that may permit development of a genetically accessible model for $M$ cell function.

The availability of a high-resolution transcriptional atlas of the zebrafish intestine, and associated tissue, allowed us to map microbial effects on each cell type. We successfully validated many known microbe-dependent events, confirming the validity of our data set. Importantly, we also uncovered a large number of unknown microbe-driven processes in the host, and resolved each process to the level of distinct cell clusters. Our work shows that the microbiota regulates growth, developmental, metabolic and immune processes across the host, displaying remarkable cellular specificity. To provide one example, we will discuss effects of the microbiota on host immune activity, however, we note our data permit identification of microbial impacts on a large number of physiological processes.

Our work revealed a hitherto unknown complexity of germline-encoded immune gene expression patterns in CV fish. Absorptive intestinal epithelial cells expressed enriched amounts of detoxifying alkaline phosphatases (Bates et al., 2006), and myeloid-activating serum amyloid A (Kanther et al., 2011; 
Murdoch et al., 2019). In contrast, progenitor and endocrine cells expressed elevated levels of the bacterial peptidoglycan sensor nod2, key NF-kB pathway elements, and il22, a cytokine that activates epithelial defenses (Dudakov et al., 2015), suggesting a refined partitioning of immune functions among epithelial cell types. Myeloid cells are characterized by elevated expression of pro-inflammatory cytokines such as il1b, tnfa and tnfb, whereas mesenchymal cells are prominent sources of immune-regulatory TGFbeta class cytokines. Comparisons between CV and GF fish uncovered a remarkable input from the microbiome on all these processes, with cell-specific expression of many immune effectors and mediators declining, relocating, or disappearing almost entirely in GF fish. This was particularly evident in the EC6 population of $\mathrm{CV}$ fish that were characterized by high levels of interferon activity in conventional conditions. Removal of the microbiome led to complete loss of EC6 enterocytes, suggesting that microbes are either critical for cell type-restricted interferon responses in the intestine, or that microbial products dictate specification of a dedicated class of interferon-positive intestinal epithelial cells.

To test developmental consequences of microbial removal on larvae, we focused on intestinal angiogenesis. In fish, the intestinal vasculature arises from angioblasts that migrate ventrally from the posterior cardinal vein, and establish a plexus that gradually resolves into the dorsal supra-intestinal artery, the ventral sub-intestinal vein, and a series of parallel vessels that connect artery and vein (Goi and Childs, 2016; Isogai et al., 2001; Lenard et al., 2015; Nicenboim et al., 2015). We noted diminished expression of key angiogenesis regulators in GF larvae, particularly VEGF-class receptors with established roles in formation of connecting vessels (Goi and Childs, 2016). Examination of GF fish showed that the microbiota is dispensable for positioning and spacing of the artery and vein. In contrast, removal of the microbiota had deleterious effects on connecting vessels, confirming a role for the microbiome in establishing the intestinal vasculature. Our results match observations from mice, where germ-free growth also diminishes villus angiogenesis (Reinhardt et al., 2012; Stappenbeck et al., 2002), suggesting a conserved requirement for microbial cues to direct intestinal angiogenesis in vertebrates. We believe the 
bioRxiv preprint doi: https://doi.org/10.1101/2020.11.06.371609; this version posted November 7, 2020. The copyright holder for this preprint (which was not certified by peer review) is the author/funder, who has granted bioRxiv a license to display the preprint in perpetuity. It is made available under aCC-BY 4.0 International license.

advances made in this study will allow us to trace the molecular, and cellular networks that control intestinal vasculogenesis in a developing vertebrate. 


\section{ACKNOWLEDGEMENTS}

We acknowledge flow cytometry support from Dr. Aja Rieger and Sabina Baghirova, as well as support with single-cell library preparation from Dr. Joaquin Lopez-Orozco. Flow Cytometry Facility Experiments were performed at the University of Alberta Faculty of Medicine \& Dentistry Flow Cytometry Facility, which receives financial support from the Faculty of Medicine \& Dentistry and Canada Foundation for Innovation (CFI) awards to contributing investigators. We also acknowledge imaging help from Dr. Xuejun Sun of the Department of Oncology Cell Imaging Facility, University of Alberta. We would also like to thank Science Animal Support Services at the University of Alberta for their excellent care of the zebrafish aquatics facility. This work was supported by grants from the Canadian Institute of Health Research (Grant \# PJT 159604). RJW has funding support through the University of Alberta Faculty of Graduate Studies and Research, National Science and Engineering Research Council Graduate Scholarships, and Alberta Innovates Graduate Student Scholarships. 


\section{MATERIALS AND METHODS}

\section{Zebrafish strains and maintenance}

Zebrafish were raised and maintained using protocols approved by the Animal Care \& Use Committee: Biosciences at the University of Alberta, operating under the guidelines of the Canadian Council of Animal Care. TL strain zebrafish were used for single-cell RNA sequencing and in situ hybridization experiments, and the $T g(k d r l: m C h e r r y)$ line (Wang et al., 2010a) was used for analysis of intestinal vasculogenesis. Fish were raised and maintained within the University of Alberta fish facility at $28^{\circ} \mathrm{C}$ under a 14 hour/ 10 hour light/ dark cycle as previously described (Westerfield, 2000).

\section{Generating germ-free zebrafish}

Fish embryos were made germ-free essentially as in Melancon et al., 2017. Embryos were collected then washed and kept in embryo media (EM) supplemented with ampicillin $(100 \mu \mathrm{g} / \mathrm{mL})$, kanamycin $(5 \mu \mathrm{g} / \mathrm{mL})$, amphotericin B $(250 \mathrm{ng} / \mathrm{mL})$, and gentamicin $(50 \mu \mathrm{g} / \mathrm{mL})$. Embryos were washed every 2 hours with EM plus antibiotics. Once at 50\% epiboly, embryos were successively washed three times in EM, then 2 minutes in $0.1 \%$ polyvinylpyrrolidone-iodine (PVP-I) in EM, followed by three EM washes, then a 20 minute incubation with $0.003 \%$ sodium hypochlorite (bleach) in EM. Embryos were washed three more times then transferred into tissue culture flasks with sterile EM. At 4 days post-fertilization, EM was collected from culture flasks then plated on TSA plates and subjected to 16S rDNA PCR to confirm absence of bacteria.

\section{Whole mount in situ hybridization}

Antisense probe generation and in situ hybridization were performed essentially as in Balay et al., 2020, where fabp2 and icn were transcribed from gene-specific PCR products with an integrated T7 RNA polymerase site (TAATACGACTCACTATAGGG) that were purified by gel extraction (Qiagen 28704). Genespecific primer sequences were as follows: fabp2 - Forward: CCTGGAAAGTCGACCGCAATG; Reverse: 
TGACATTGGGAGTGCAGATAACA; icn - Forward: TTCCTTTCACTTGTTGCCCATCG; Reverse: TGCAAAGCATTGTGATACAGGCAA. For hybridization, $6 \mathrm{dpf}$ larvae were fixed in $4 \%$ paraformaldehyde (PFA) in PBS overnight at $4^{\circ} \mathrm{C}$, then washed in PBS+0.1\% Tween-20. Larvae were permeabilized with $10 \mu \mathrm{g} / \mathrm{ml}$ Proteinase K (Sigma P4850) in PBST for $45 \mathrm{~min}$ at room temperature (RT), then re-fixed in $4 \%$ PFA for 20 min. Larvae were then hybridized with antisense probes overnight at $65^{\circ} \mathrm{C}$, subjected to high stringency saline sodium citrate (SSC) washes, blocked for 2 hours at RT in $2 \mathrm{mg} / \mathrm{ml}$ bovine serum albumin (BSA; Roche 10735086001) and 2\% sheep serum (Sigma S2263) in PBST, followed by a $4^{\circ} \mathrm{C}$ overnight incubation with anti-DIG-AP antibody (Roche 11093274910) in blocking buffer. Larvae were colored using NBT/BCIP (Roche 11383213001, 11383221001) for approximately 30 min at RT (both fabp2 and icn). Colorization reactions were stopped with four washes in PBST, pH 5.5. Larvae were then cleared in $30 \%$, $50 \%$ and $70 \%$ glycerol in PBS, then eyes were removed, and larvae were mounted in $70 \%$ glycerol for imaging on a ZEISS Axio Observer. Image brightness and contrast was adjusted in FIJI.

\section{Imaging and quantifying intestinal vasculature}

$T g$ (kdrl:mCherry) fish (Wang et al., 2010a) were raised under conventional or germ-free conditions for 6 $\mathrm{dpf}$, then euthanized with tricaine and fixed overnight at $4^{\circ} \mathrm{C}$. Larvae were washed $3 \mathrm{X}$ in PBS then embedded in $0.7 \%$ UltraPure low melting point agarose (Invitrogen 16520) on a glass bottom dish. Tile and Z-stack images ( $5 \mu \mathrm{m}$ sections) of whole fish were captured on a Leica Falcon SP8 equipped with a 25x 0.95NA Water HC Fluotar objective lens. Images were stitched with Leica Application Suite X software (Leica) and imported to FIJI to produce maximum intensity Z-projection images that were adjusted for brightness and contrast, as well as false color manipulations. To quantify intestinal vasculature, corresponding brightfield images were used to set intestinal boundaries in FIJI. Fluorescent images were then converted to binary images and the area of kdrl:mCherry signal relative to the area of the whole intestine was measured. Box plots were generated in RStudio with ggplot2. 


\section{Generating single-cell suspension for single cell RNA-seq}

Zebrafish 6 days post-fertilization were euthanized in PBS plus tricaine, then intestines were immediately dissected and placed into PBS on ice until 25 intestines were collected per condition, with dissection time kept below 2 hours. Intestines were incubated in a dissociation cocktail of $1 \mathrm{mg} / \mathrm{mL}$ fresh collagenase A, $40 \mu \mathrm{g} / \mathrm{mL}$ proteinase $\mathrm{k}$, and $0.25 \%$ trypsin for 30 minutes at $37^{\circ} \mathrm{C}$, pipetting up and down every 10 minutes to aid digestion. ZombieAqua viability dye (BioLegend) was added to a final concentration of 1:1000 to stain dead and dying cells. Next, BSA was added to a final concentration of $1 \%$ to stop digestion, and the cells were spun at $0.3 \mathrm{RCF}$ at 4 으 to pellet cells. Cells were re-suspended in PBS+0.04\% BSA and spun down through a $40 \mu \mathrm{m}$ cell strainer (Pluriselect). Filtered cells were immediately sorted on a BD FACS Aria III to collect live single cells, then counted with a hemocytometer. Viability, as determined with Trypan blue, was $>95 \%$ for both CV and GF samples. The single cell suspension was then run through the $10 \mathrm{X}$ Genomics Chromium Controller with Chromium Single Cell 3' Library \& Gel Bead Kit v3. Libraries were constructed according to the manufacturer's protocol then sent to Novogene for sequencing on the HiSeq system.

\section{Processing and analysis of single cell RNA-seq data}

For single cell analysis, Cell Ranger v3.0 (10X Genomics) was used to demultiplex raw base call files from Illumina sequencing and to align reads to the Zebrafish reference genome (Ensembl GRCz11.96). These matrices were analyzed using the Seurat R package version 3.1.1 (Butler et al., 2018) in RStudio. Cells possessing fewer than 200 UMIs, greater than 2500 UMIs, or greater than $50 \%$ mitochondrial reads were removed to reduce the number of low-quality cells and doublets. Seurat was then used to normalize expression values and perform cell clustering at a resolution of 1.0 with 20 principal components. The same parameters were used for independent and integrated sample analyses. After using the "FindMarkers" function in Seurat to identify marker genes for each cluster, clusters were annotated according to known epithelial or extra-intestinal markers in zebrafish, or orthologous markers in 
mammals. Where cluster identities were not immediately obvious, functional analysis via gene ontology enrichment scores was used to ascribe cell identity.

\section{Guided identification of LREs}

To manually cluster LREs in the conventionally reared dataset, we subset cells with log normalized expression of $d a b 2>0.1$ and $s / c 15 a 2>1.0$. This method isolated five LREs. Seurat requires 10 cells to make a cluster, thus LREs were not identified during initial clustering.

\section{Lineage trajectory construction}

Developmental trajectory analysis was performed in the STREAM (Single-cell Trajectories Reconstruction, Exploration And Mapping) package for bioconda, version 0.4.0 (Chen et al., 2019). Analysis was run on single epithelial cells profiles exported from Seurat post-QC. Lowly expressed genes and genes expressed in fewer than 5 cells were filtered further in STREAM, then variable genes were identified. The dimensionality of the dataset was reduced using the top 10 principal components, and trajectory inference was run using k-means clustering with 5 initial clusters. Inferred trajectories were then visualized using stream plots, with progenitor-like cells at the root. Transition genes for each branch of the trajectory (Figure S4) were detected with "st.detect transition markers", using default parameters.

\section{Gene ontology (GO) enrichment analysis}

Marker genes from single datasets ( $p$-value cut-off $<0.05$ ), as well as up- and down-regulated gene lists from the integrated dataset ( $p$-value cut-off $<0.05$ ) were analyzed in GOrilla (Gene Ontology enRIchment analysis and visualizAtion tool) to determine GO term enrichment (Eden et al., 2009). Genes were analyzed in a two-list unranked comparison using the whole dataset gene list as background. To remove redundant GO terms, enriched terms with associated p-values from GOrilla were run through REVIGO (REduce and VIsualize Gene Ontology) using SimRel semantic similarity metric with an allowed similarity 
bioRxiv preprint doi: https://doi.org/10.1101/2020.11.06.371609; this version posted November 7, 2020. The copyright holder for this preprint

(which was not certified by peer review) is the author/funder, who has granted bioRxiv a license to display the preprint in perpetuity. It is made available under aCC-BY 4.0 International license.

of 0.4 (Supek et al., 2011). Only top enriched terms are shown in each plot, as well as those same GO terms when found in other clusters (for Figures 2 and 4). Bar plots and bubble plots were manually generated using ggplot2 in RStudio. 


\section{SUPPLEMENTARY MATERIAL}

A
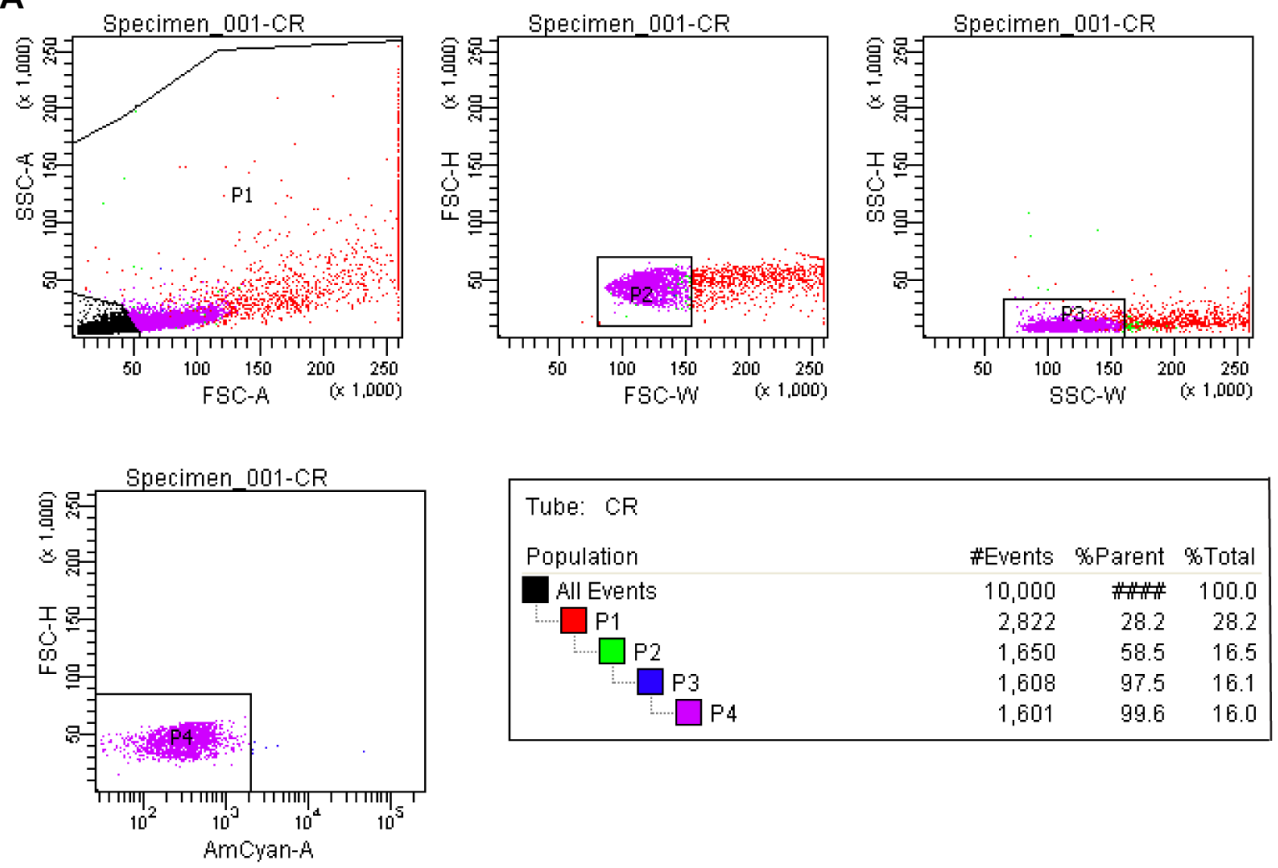

B
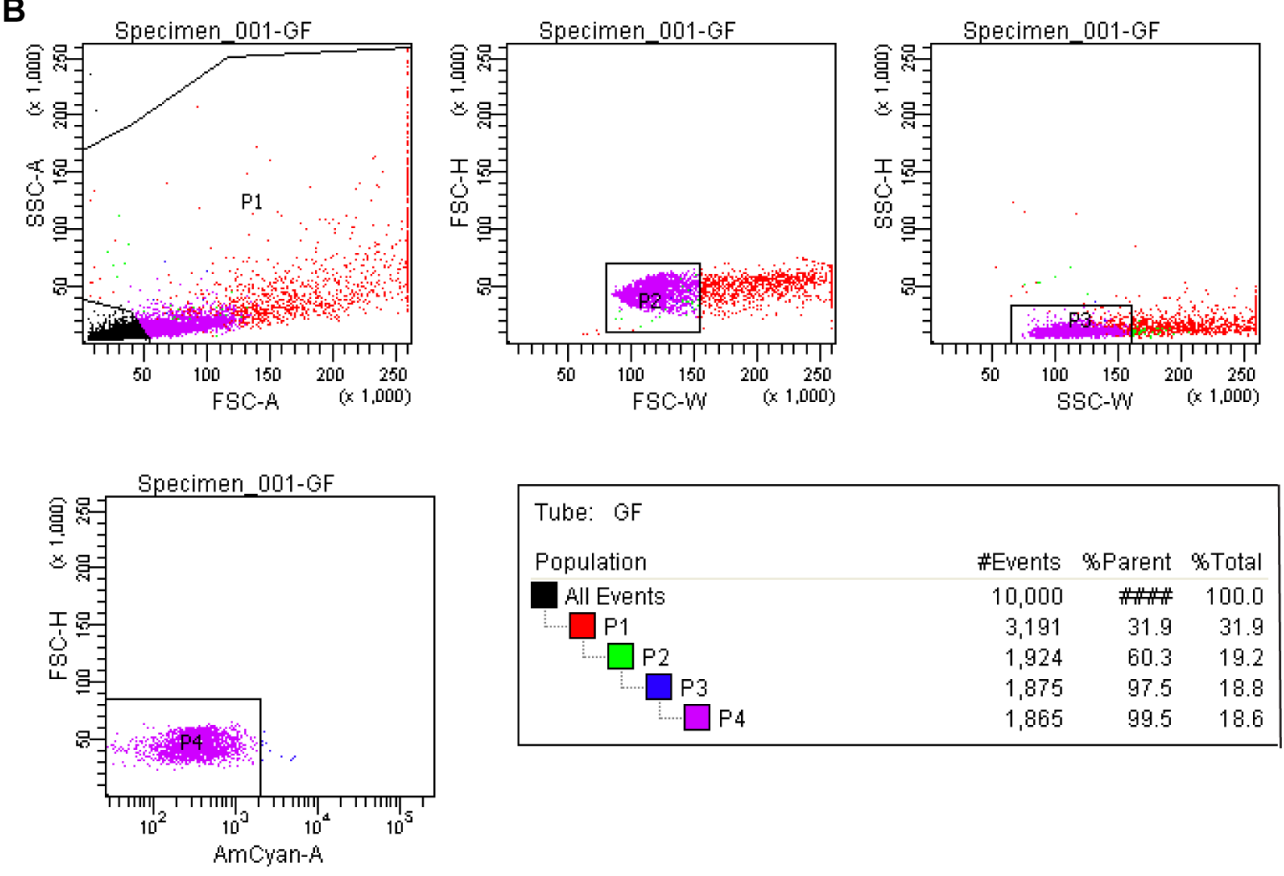

Figure S1. Isolation of single cells via fluorescence activated cell sorting. $(A-B)$ Gating strategy for isolating dissociated single intestinal cells from CV (A) and GF (B) fish. Forward and side scatter were used to determine the single cell population, and Zombie Aqua viability die was used to select live cells. 
bioRxiv preprint doi: https://doi.org/10.1101/2020.11.06.371609; this version posted November 7, 2020. The copyright holder for this preprint (which was not certified by peer review) is the author/funder, who has granted bioRxiv a license to display the preprint in perpetuity. It is made available under aCC-BY 4.0 International license.

\section{A}

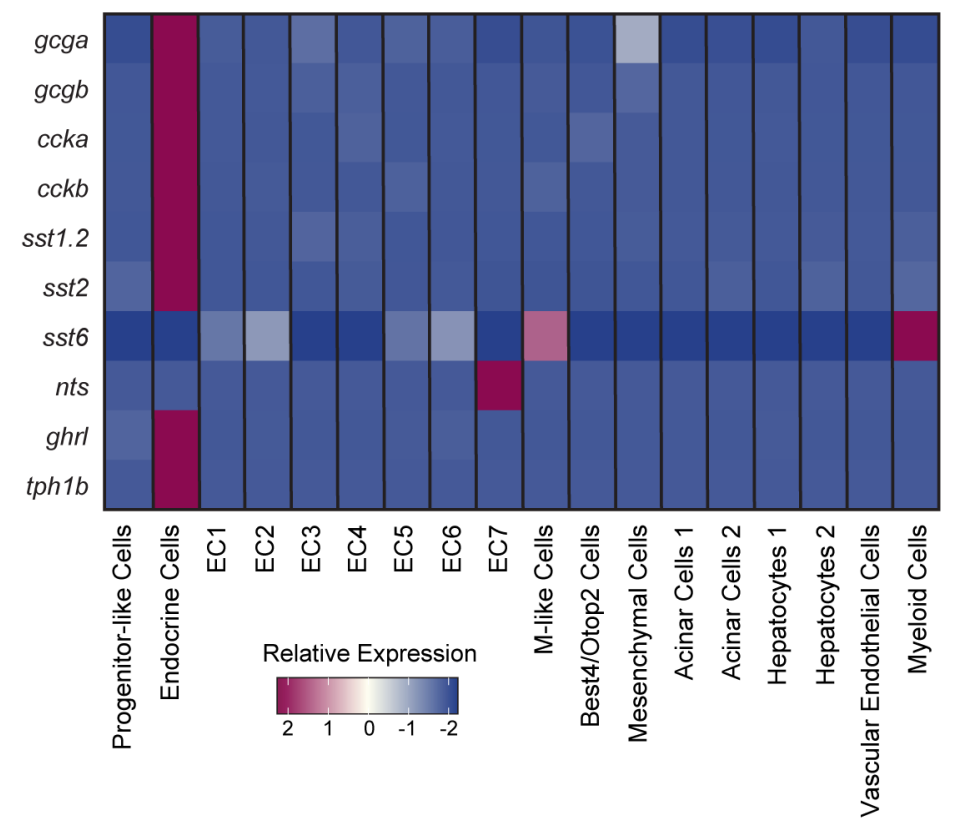

B

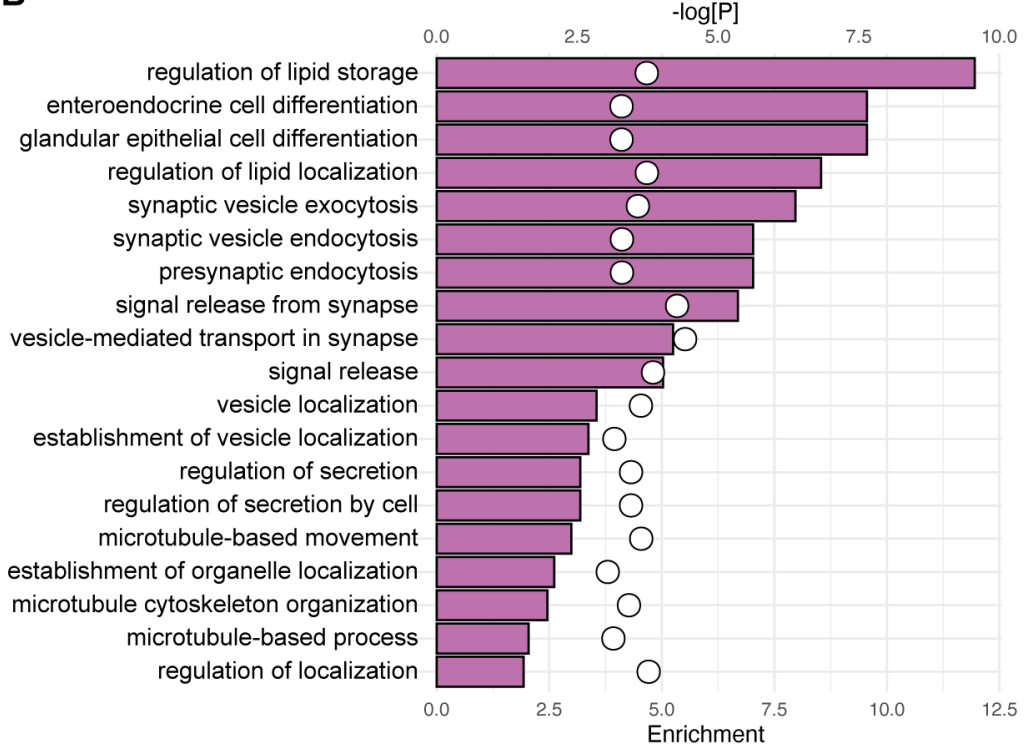

Figure S2. Endocrine cells are enhanced for signal transduction by peptide hormones. $(A)$ Heatmap showing relative expression of peptide hormones in intestinal cell populations. $(B) \mathrm{GO}$ enrichment analysis of endocrine cells based on marker genes. Enrichment score is represented by bar length and P-value is indicated with white circles. 
bioRxiv preprint doi: https://doi.org/10.1101/2020.11.06.371609; this version posted November 7, 2020. The copyright holder for this preprint (which was not certified by peer review) is the author/funder, who has granted bioRxiv a license to display the preprint in perpetuity. It is made available under aCC-BY 4.0 International license.

A

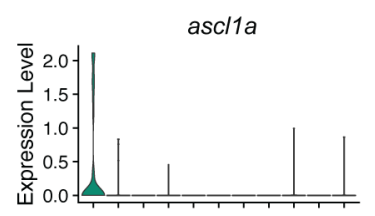

myb

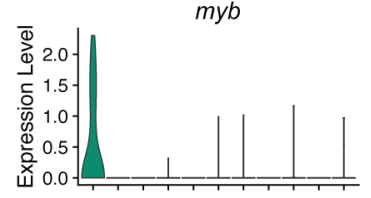

B

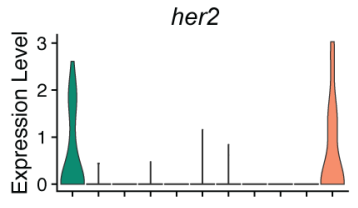

her15.1

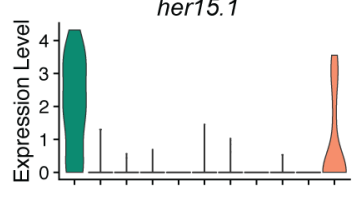

atoh1b

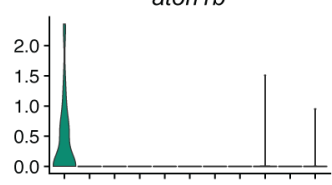

$\operatorname{sox} 4 a .1$
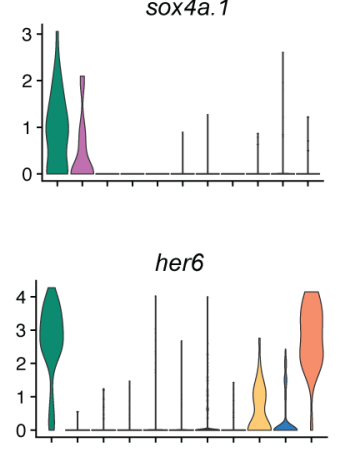

her15.2

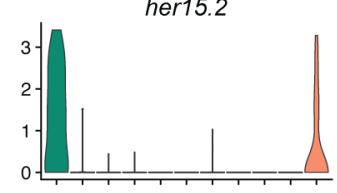

dld

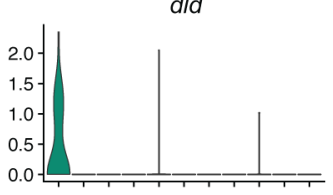

sox $4 b$

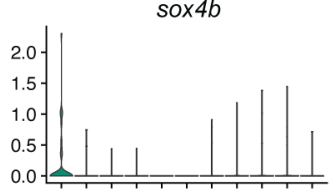

her9

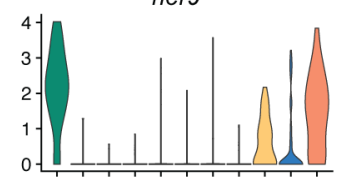

tnfrsf11a

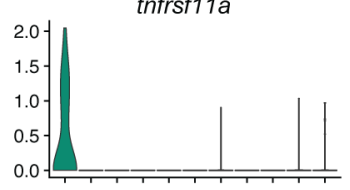

Progenitor-like Cells

Endocrine Cells

EC1

$\mathrm{EC} 2$

EC3

EC4

EC4

EC5

EC6

EC7

M-like Cells

Best4/Otop2 Cells

Figure S3. Progenitor-like cells are enriched for epithelial cell differentiation factors. Log normalized expression values for genes required for intestinal secretory cell differentiation $(A)$ or absorptive cell specification $(B)$. 
A

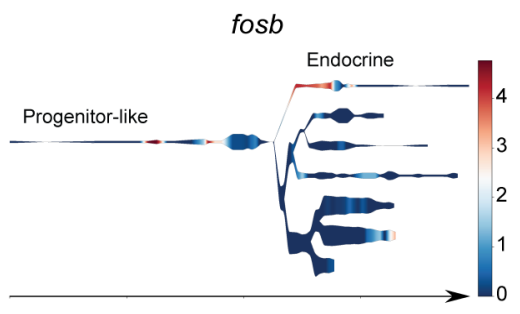

B

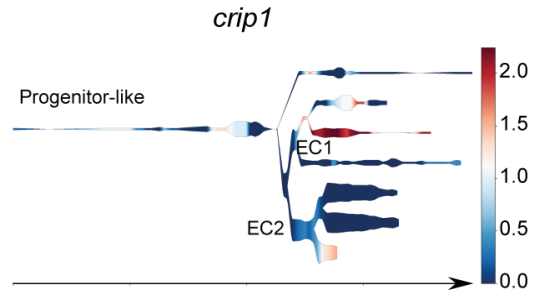

C

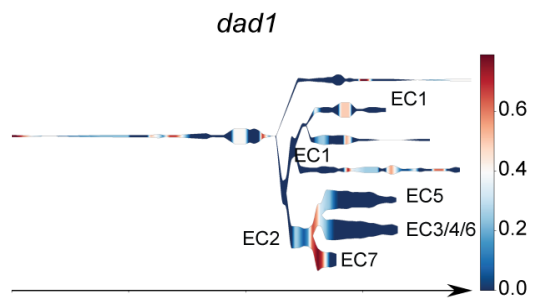

D

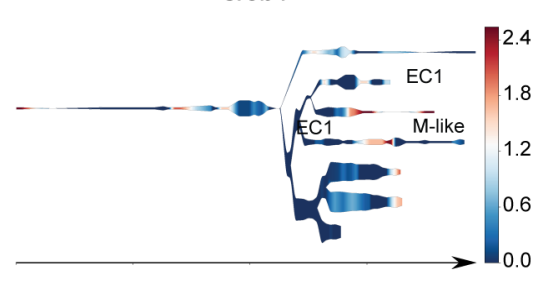

hexim1

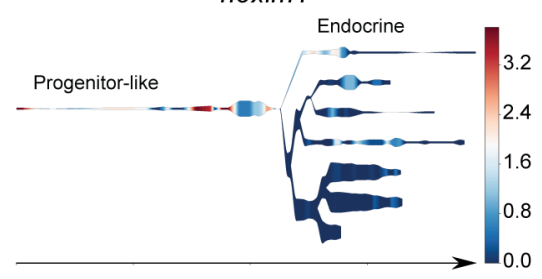

$p d x 1$
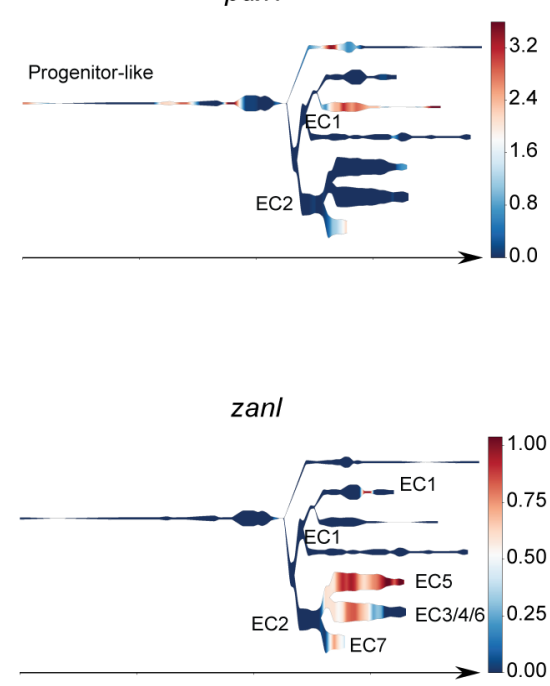

cst3

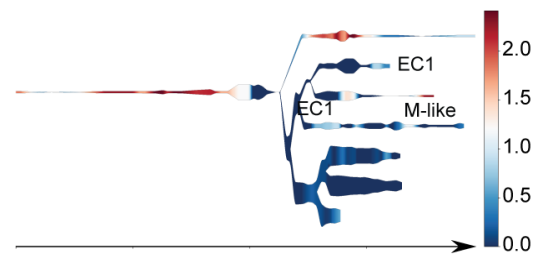

Figure S4. Transition genes define lineage trajectories. $(A-D)$ Single-cell trajectory reconstruction of epithelial lineages, where expression of genes upregulated during cell state transitions is shown. fos $b$ and hexim1 are upregulated at the transition from progenitor-like cells to endocrine cells (A), crip1 and $p d x 1$ are putative regulators of differentiation from progenitor-like cells to EC1 (B), dad1 and zanl were identified as genes that mediate the transition from early EC2 to ECs 3-7 (C), and sf3b1 and cst3 are upregulated at the transition from EC1 to M-like cell (D). 
bioRxiv preprint doi: https://doi.org/10.1101/2020.11.06.371609; this version posted November 7, 2020. The copyright holder for this preprint (which was not certified by peer review) is the author/funder, who has granted bioRxiv a license to display the preprint in perpetuity. It is made available under aCC-BY 4.0 International license.

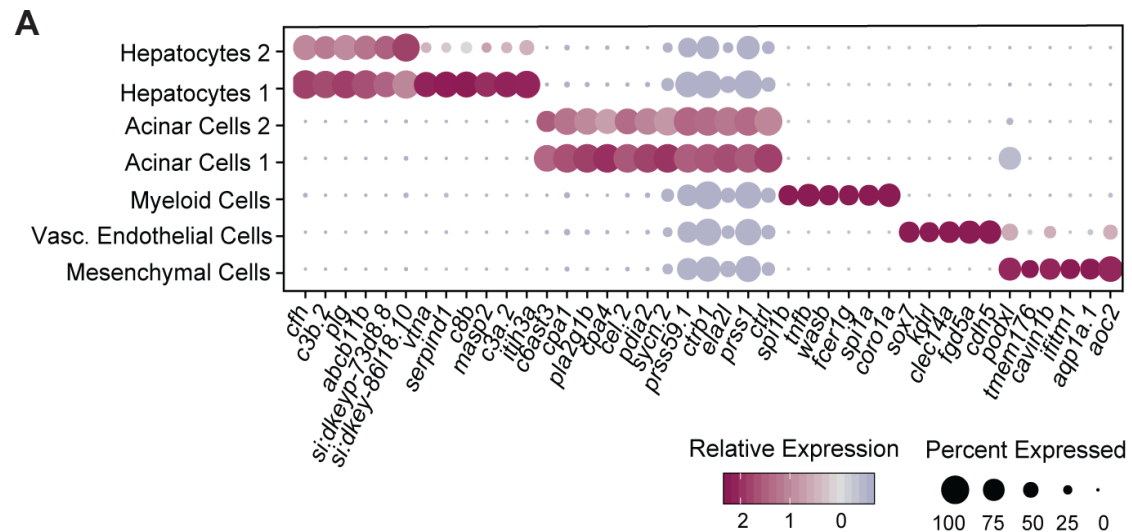

B

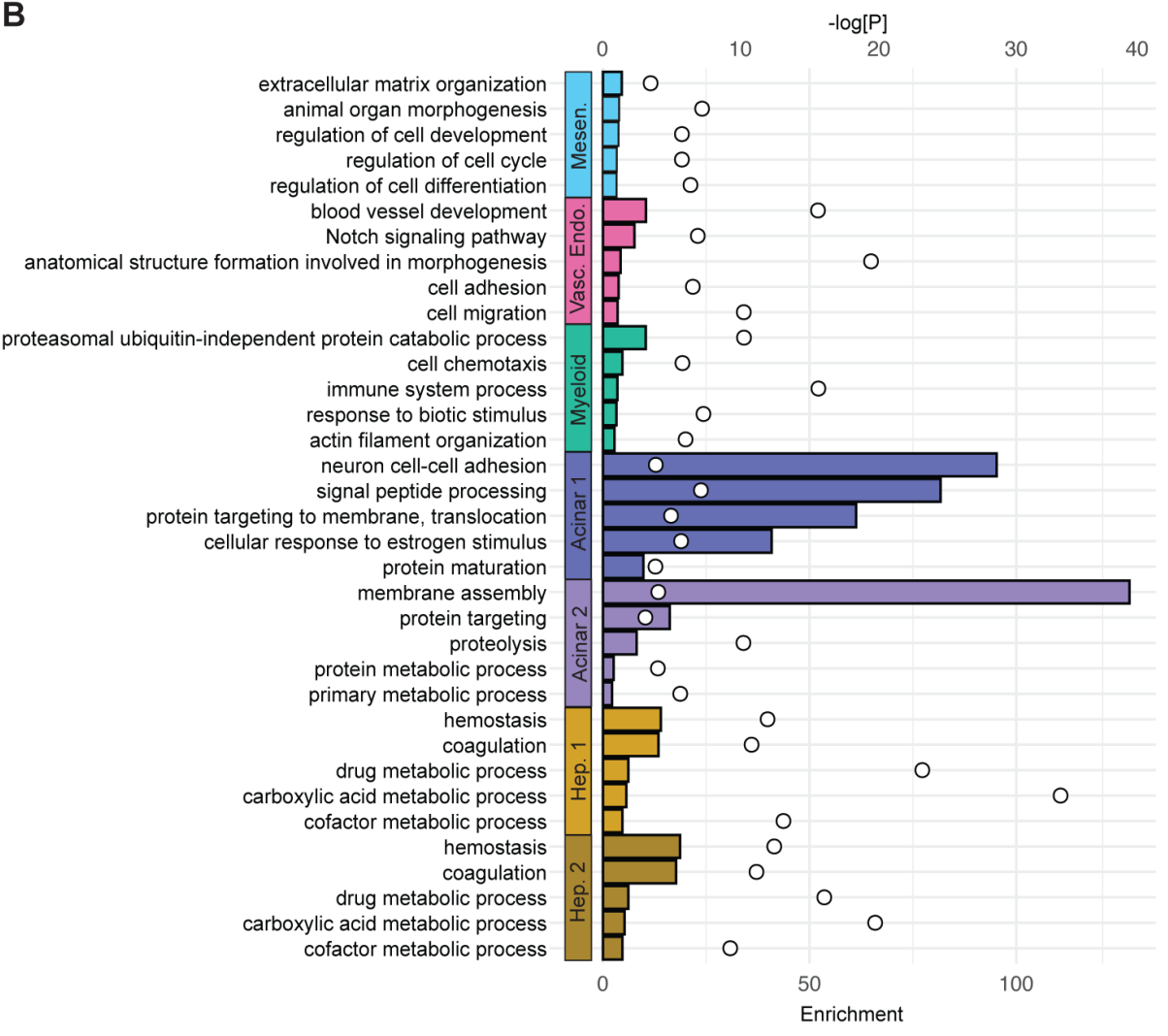

Figure S5. The intestine contains genetically and functionally distinct extra-intestinal cell populations. (A) Heatmap of cluster markers colored by relative gene expression. The size of the dot indicates proportion of expressing cells per cell type. (B) Gene ontology (GO) enrichment analysis of extra-intestinal cell types based on genetic markers. Top $5 \mathrm{GO}$ terms are shown. Enrichment score is represented by bar length and $\mathrm{P}$-value is indicated with white circles. 
bioRxiv preprint doi: https://doi.org/10.1101/2020.11.06.371609; this version posted November 7, 2020. The copyright holder for this preprint (which was not certified by peer review) is the author/funder, who has granted bioRxiv a license to display the preprint in perpetuity. It is made available under aCC-BY 4.0 International license.

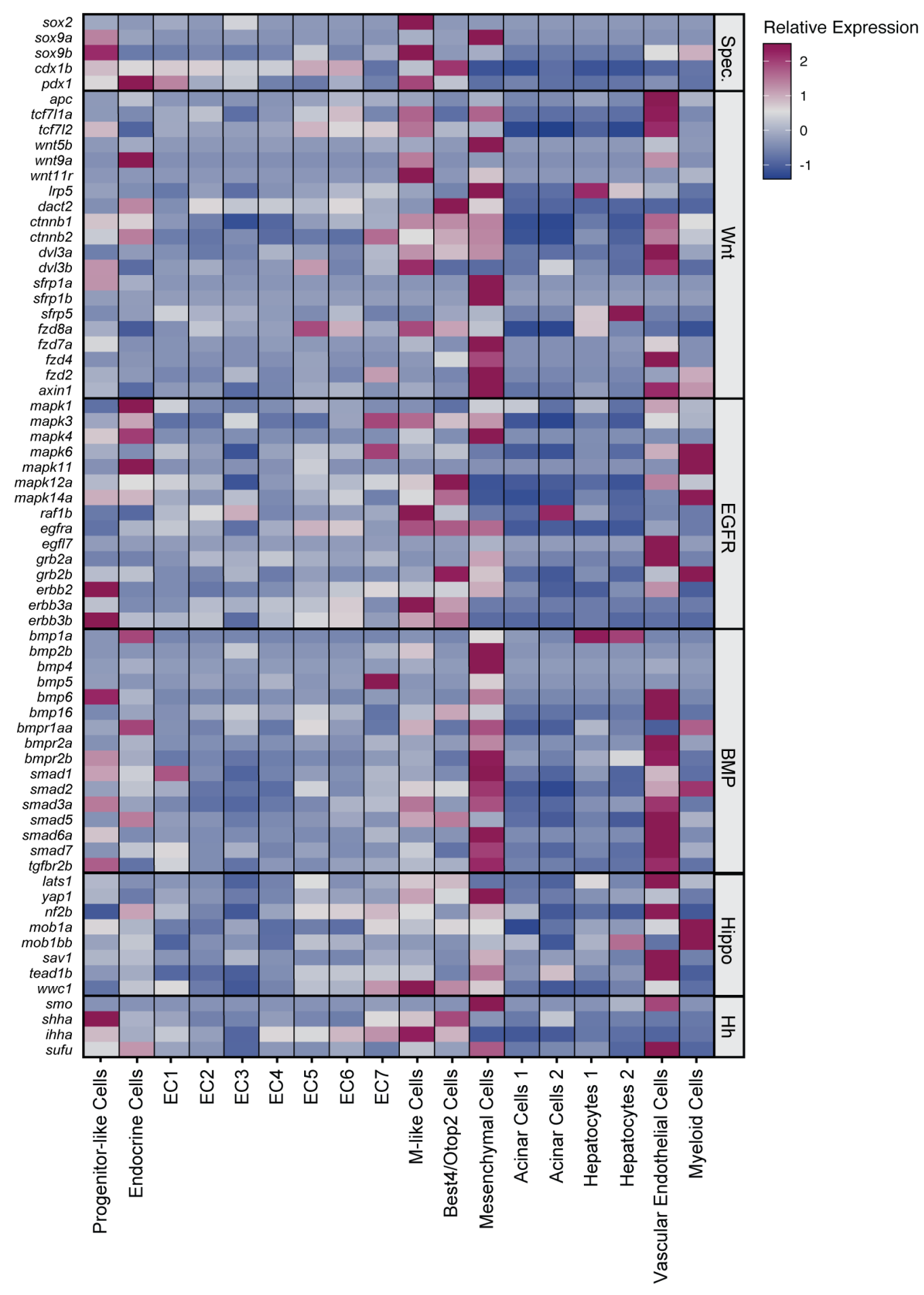

Figure S6. Growth and differentiation pathways are enriched across intestinal cell types. Heatmap showing relative expression of genes in selected growth and differentiation pathways across intestinal cell populations. Spec. = specification pathways; $\mathrm{Hh}=$ hedgehog. 
A

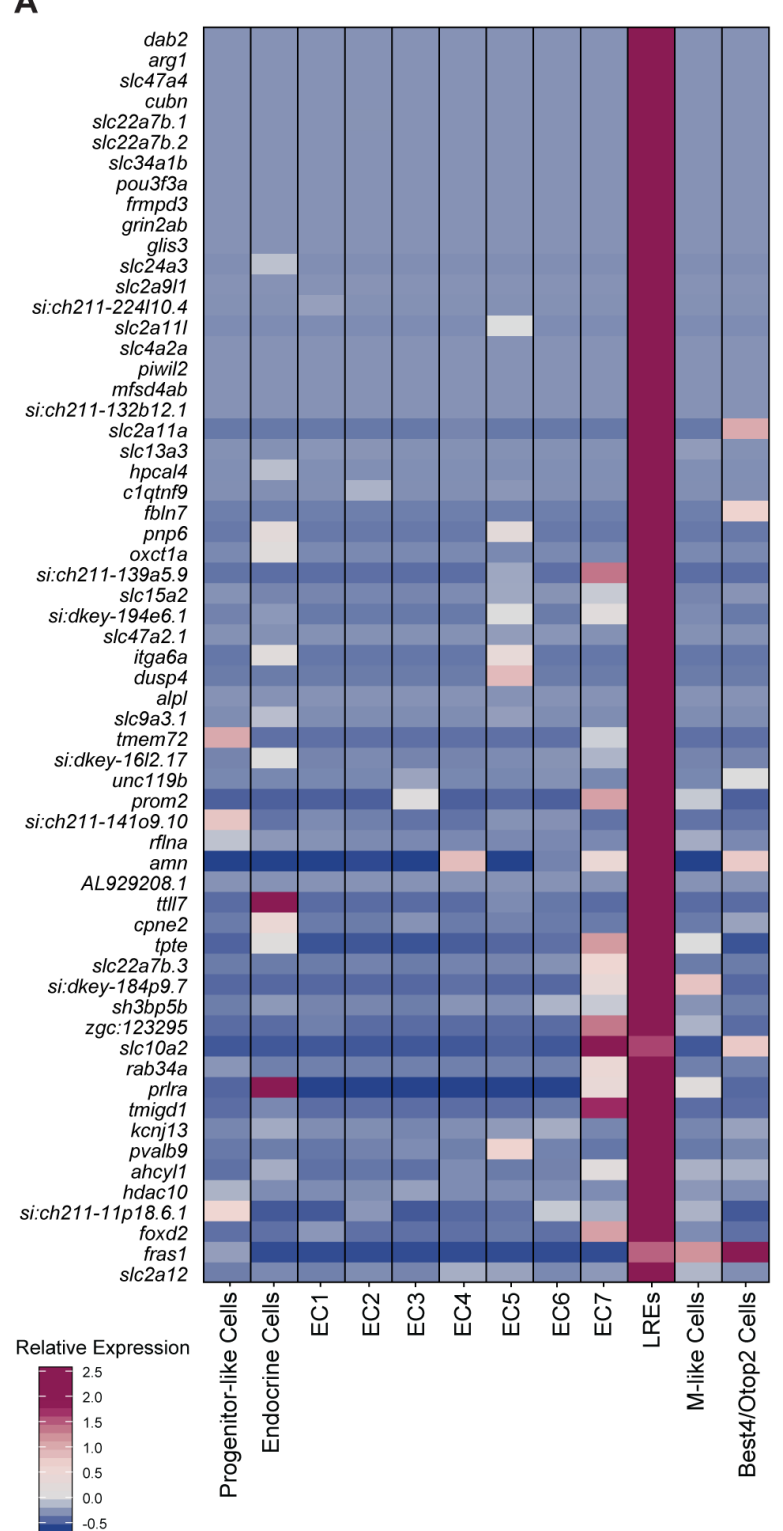

B

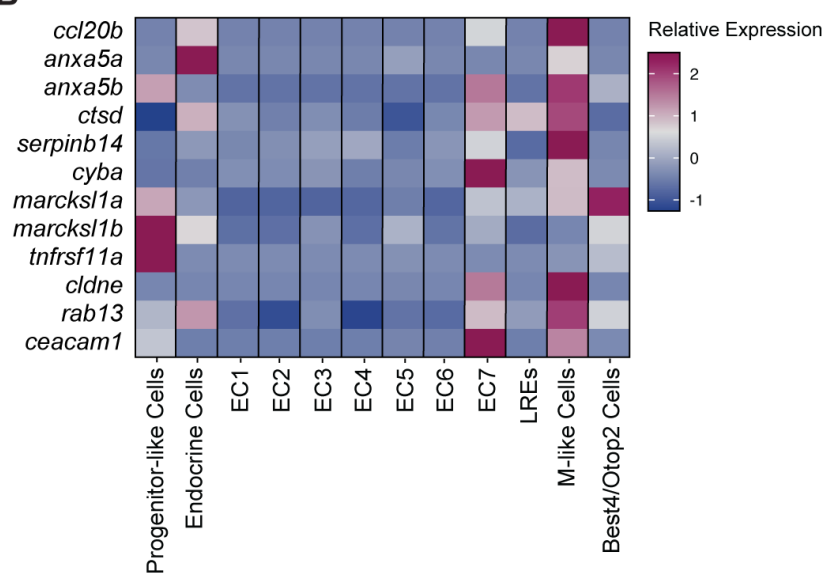

C

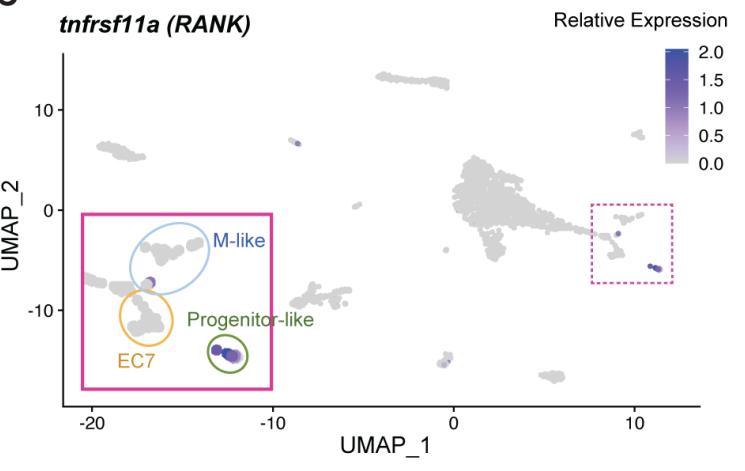

Figure S7. Genetic characterization of LRE and M-like cell populations. $(A)$ Heatmap showing relative expression of LRE marker genes, where LREs were manually identified by upregulation of described LRE markers dab2 and s/c15a2. (B) Heatmap showing relative expression of zebrafish orthologues to mammalian M cell markers. (C) Feature plot where relative cell-specific expression of tnfrsf11a (RANK) is indicated by color. Inset shows annotated cell populations. 
bioRxiv preprint doi: https://doi.org/10.1101/2020.11.06.371609. this version posted November 7, 2020. The copyright holder for this preprint (which was not certified by peer review) is the author/funder, who has granted bioRxiv a license to display the preprint in perpetuity. It is made available under aCC-BY 4.0 International license.

A
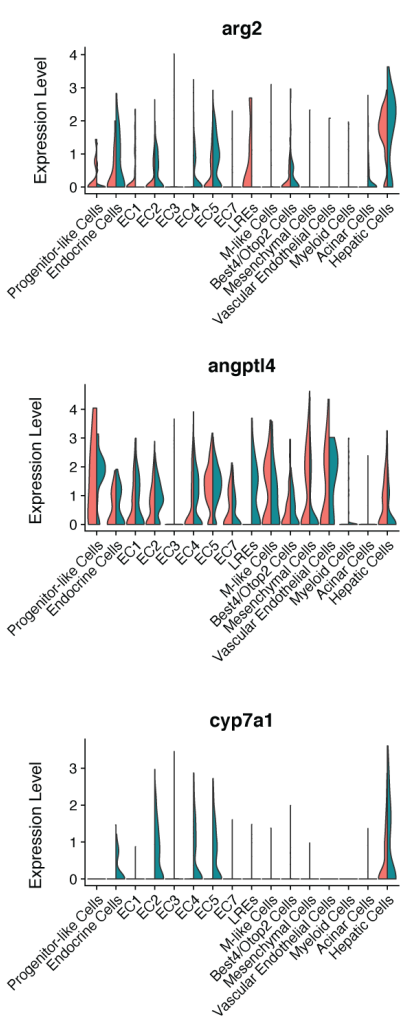

B
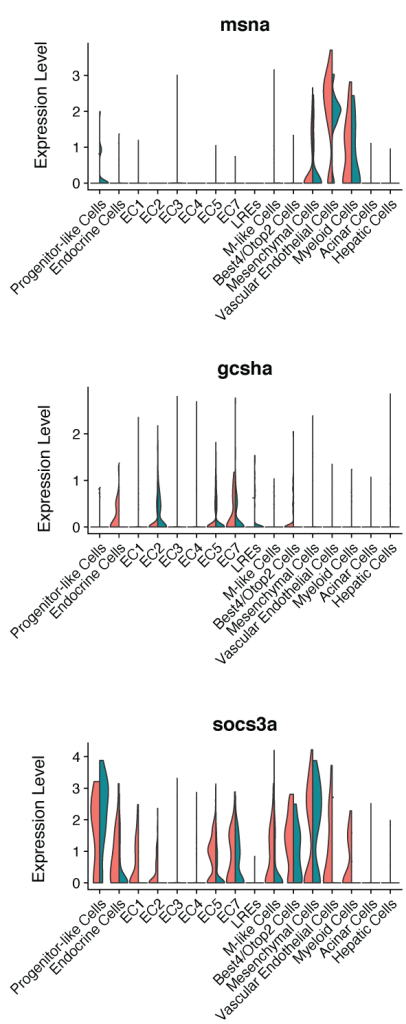
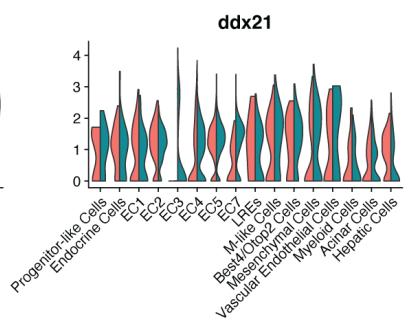

cpt1ab
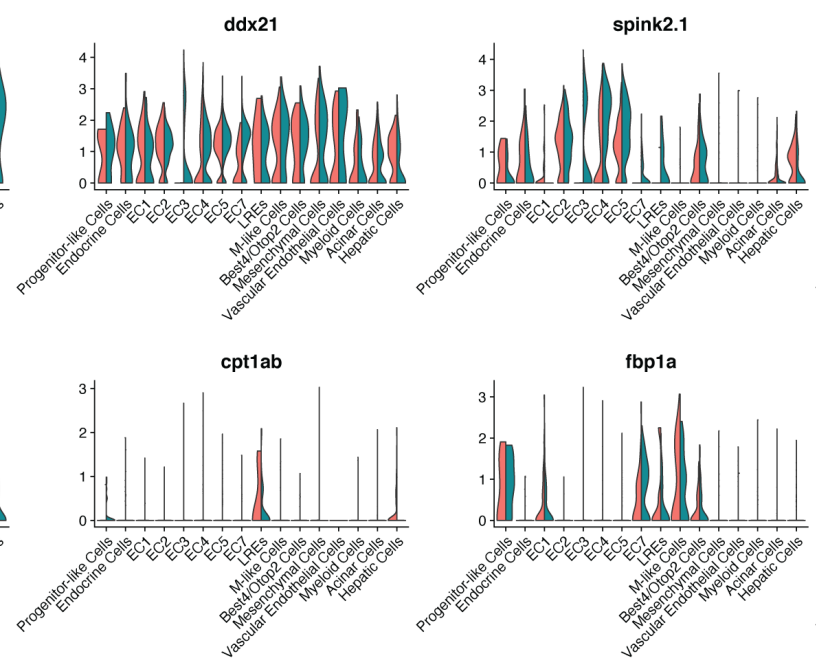

fbp1a
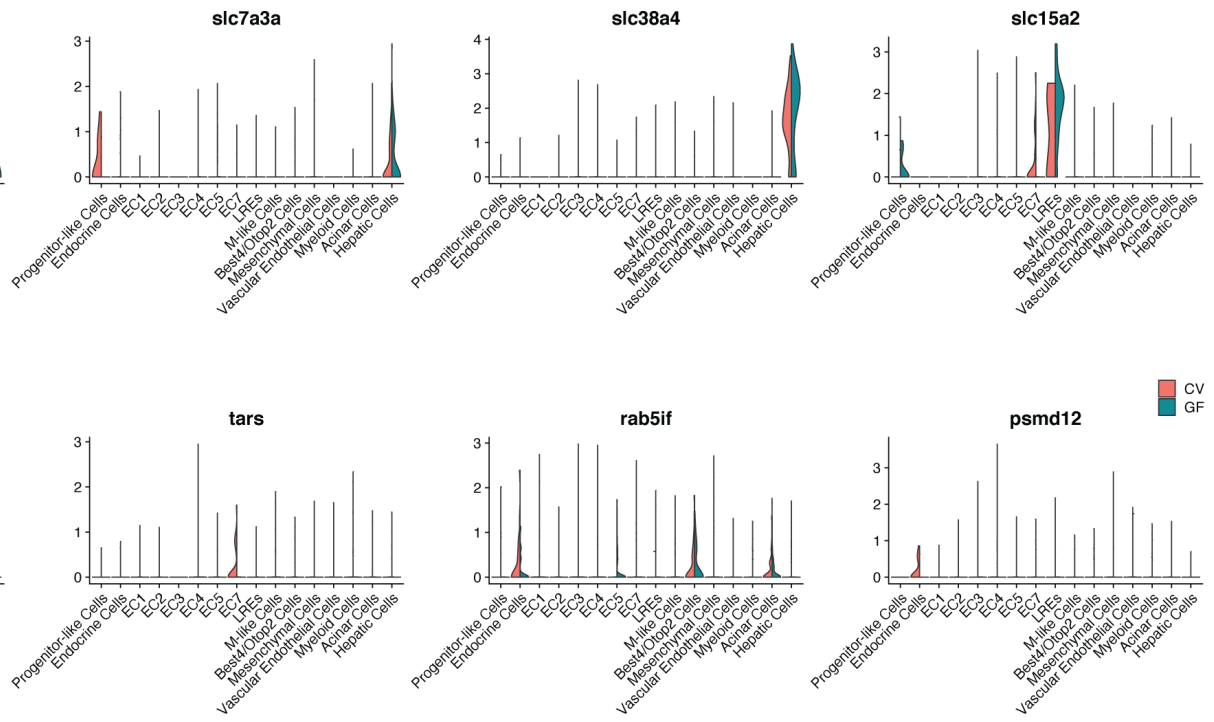

pcna
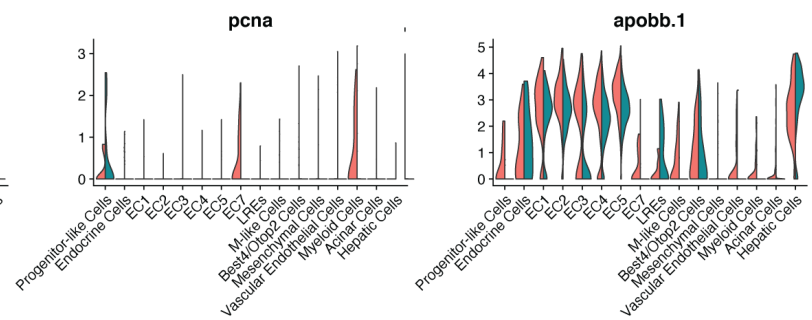

gpx1b
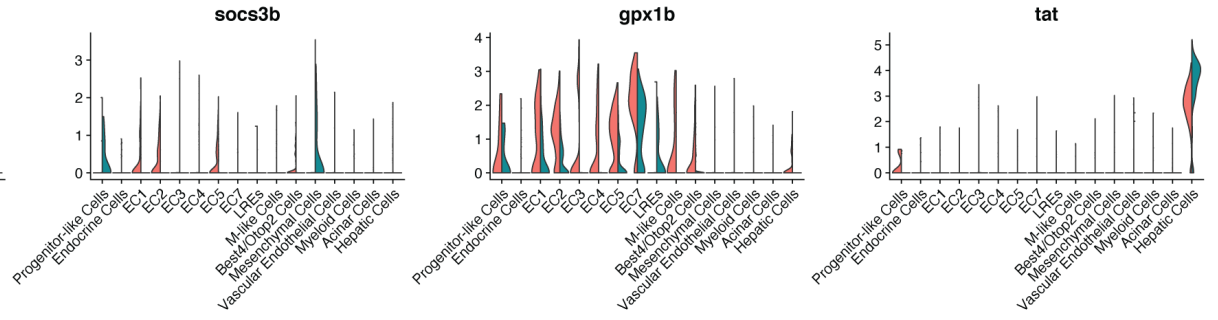

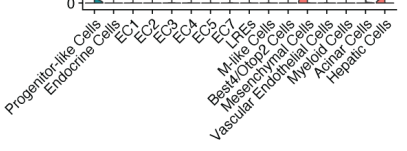

fbp1b

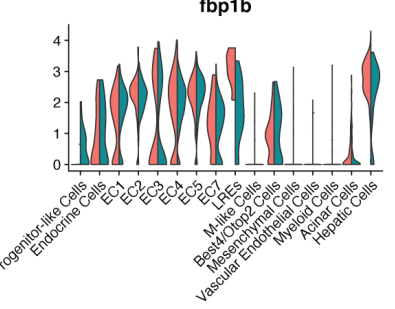

$c \mathrm{~V}$ 
bioRxiv preprint doi: https://doi.org/10.1101/2020 11.06.371609; this version posted November 7, 2020. The copyright holder for this preprint (which was not certified by peer review) is the author/funder, who has granted bioRxiv a license to display the preprint in perpetuity. It is made available under aCC-BY 4.0 International license.

Figure S8. Microbe-responsive genes exhibit cell-specific changes upon bacterial colonization. Comparison of log normalized expression for known microbe-responsive genes in all intestinal cell types under CV and GF conditions. Genes whose expression increases in GF relative to CV fish intestines are shown in $(A)$ while genes whose expression decreases in GF relative to CV fish intestines are shown in $(B)$. 
bioRxiv preprint doi: https://doi.org/10.1101/2020.11.06.371609; this version posted November 7, 2020. The copyright holder for this preprint (which was not certified by peer review) is the author/funder, who has granted bioRxiv a license to display the preprint in perpetuity. It is made available under aCC-BY 4.0 International license.

A

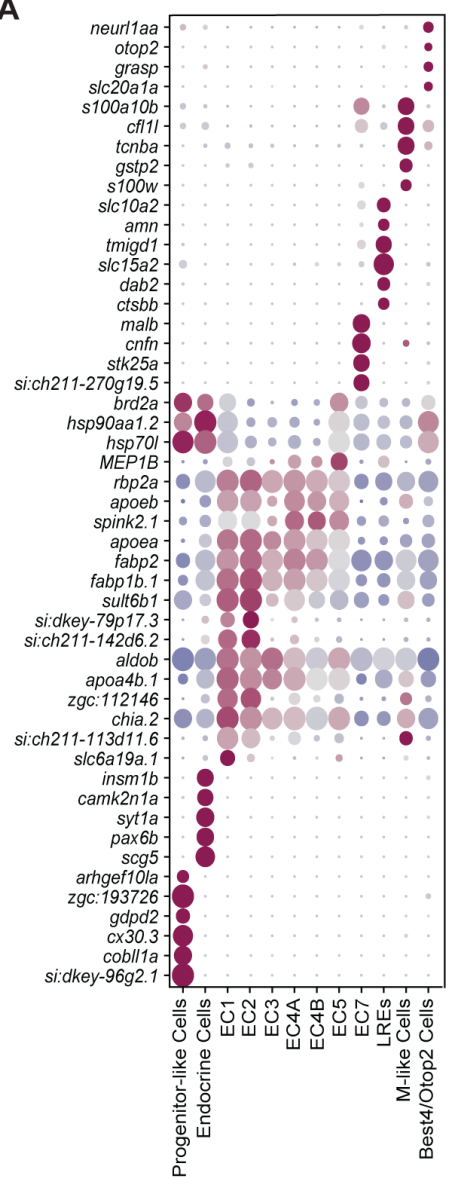

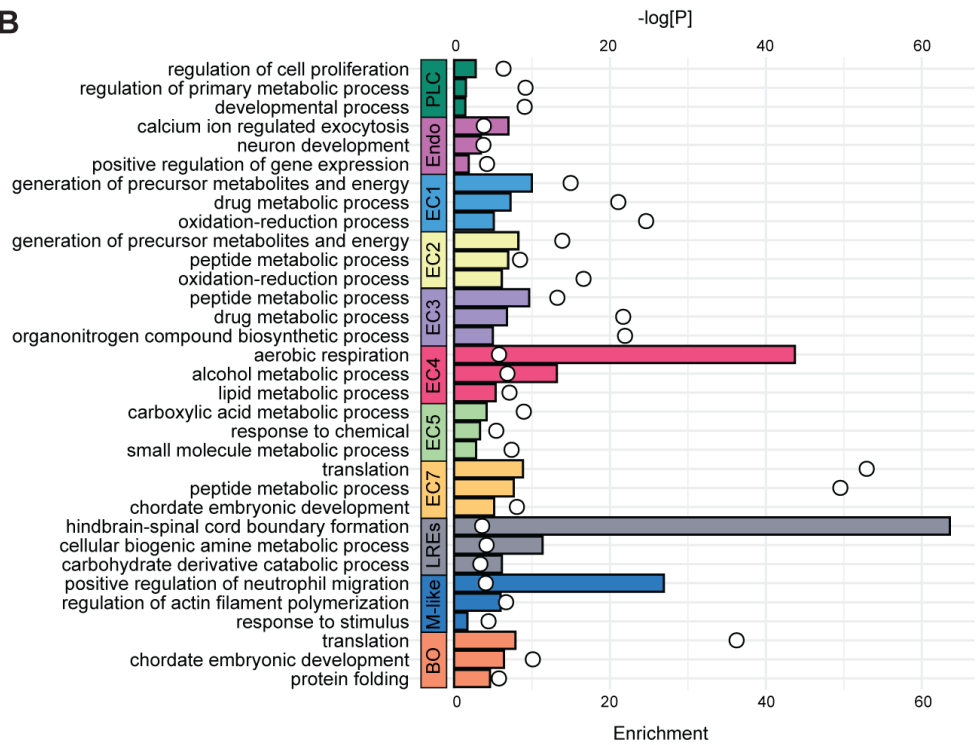

C

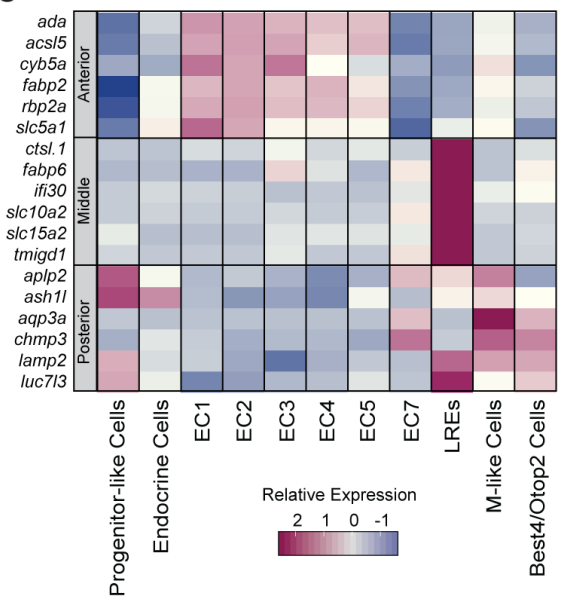

D

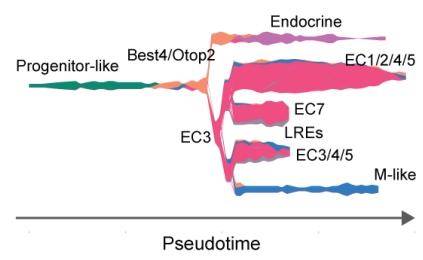

Relative Expression Percent Expressed

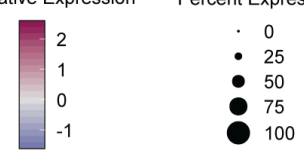

E

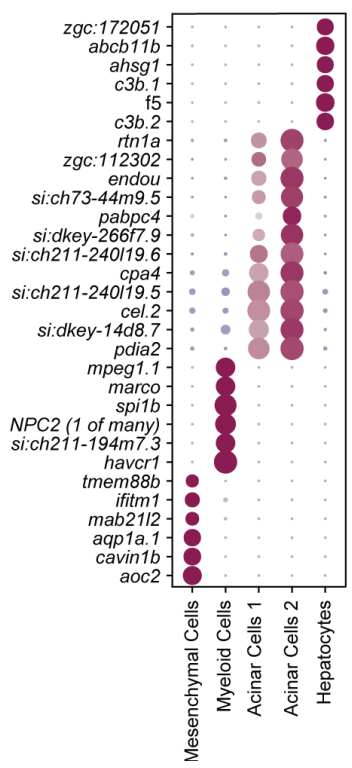

$\mathrm{F}$

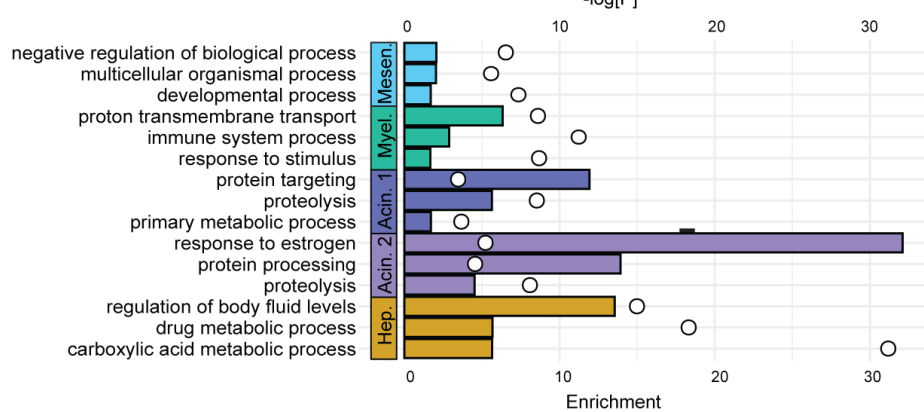

Relative Expression Percent Expressed

$\begin{array}{ll}\cdot & 0 \\ - & 25\end{array}$

- 250

75
100 
Figure S9. Germ-free fish maintain diverse intestinal cell populations. $(A, E)$ Heatmap of cluster markers for intestinal epithelial (A) or extra-intestinal cell types (E) colored by relative gene expression. The size of the dot indicates proportion of expressing cells per cell type. $(B, F)$ Top 3 enriched non-redundant $G O$ terms per epithelial cell type $(C)$ or extra-intestinal cell type $(E)$ based on genetic markers. Enrichment score is represented by bar length and P-value is indicated with white circles. (C) Heatmap showing relative expression of established regional marker genes in each epithelial cell type. $(D)$ Single-cell trajectory reconstruction of epithelial lineages. 
bioRxiv preprint doi: https://doi.org/10.1101/2020.11.06.371609; this version posted November 7, 2020. The copyright holder for this preprint (which was not certified by peer review) is the author/funder, who has granted bioRxiv a license to display the preprint in perpetuity. It is made available under aCC-BY 4.0 International license.

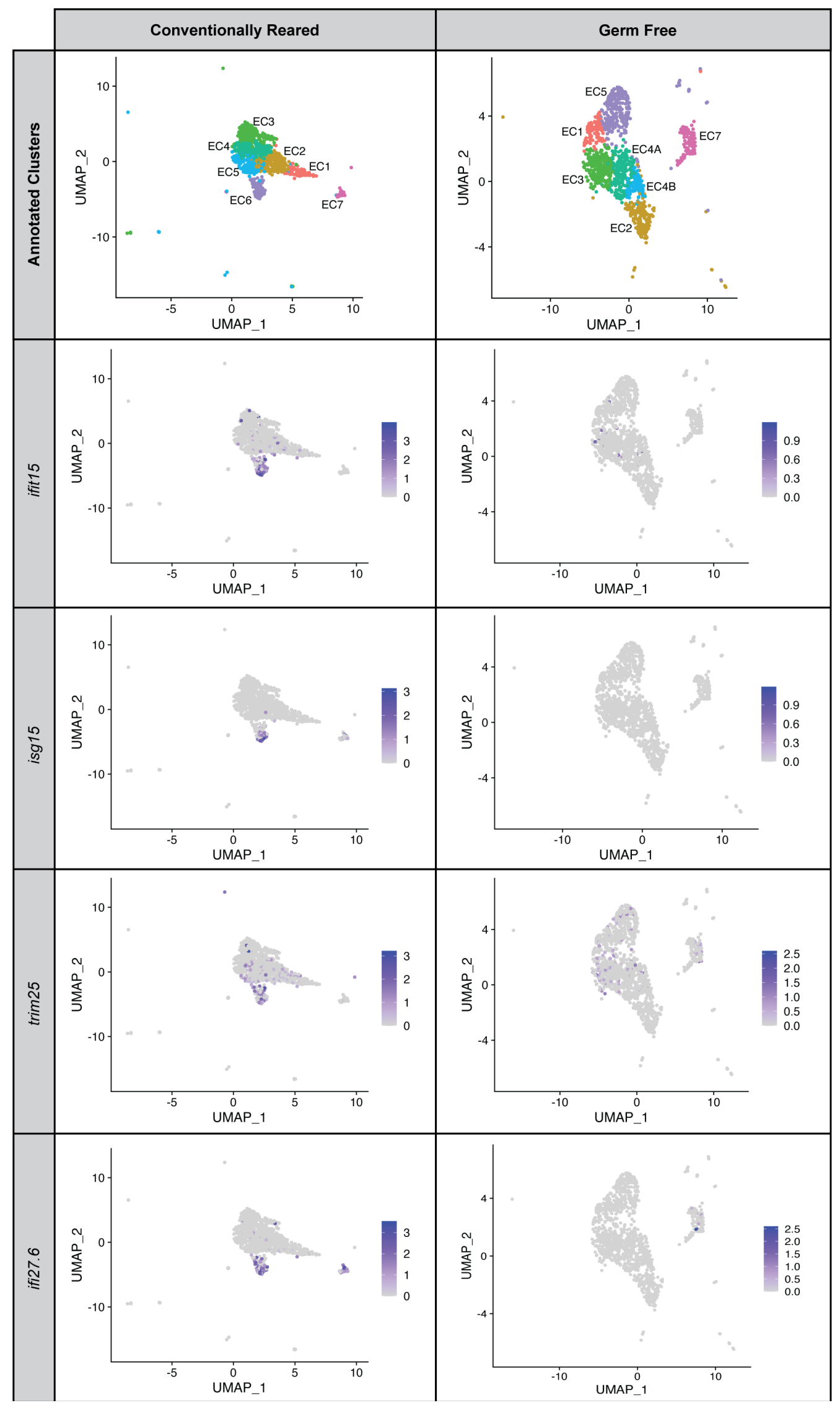


bioRxiv preprint doi: https://doi.org/10.1101/202011.06.371609; this version posted November 7, 2020. The copyright holder for this preprint (which was not certified by peer review) is the author/funder, who has granted bioRxiv a license to display the preprint in perpetuity. It is made available under aCC-BY 4.0 International license.

Figure S10. Microbes stimulate IFN-enriched enterocytes. UMAP plots of enterocytes are shown under CV or GF conditions, with color coded annotated clusters or with relative cell-specific expression of genes involved in IFN signaling that are markers of CV EC6. ifit15 is orthologous to human IFIT2, isg15 is orthologous to human ISG15, and trim25 is orthologous to human TRIM25. 


\section{REFERENCES}

Arora, T., Akrami, R., Pais, R., Bergqvist, L., Johansson, B.R., Schwartz, T.W., Reimann, F., Gribble, F.M., and Bäckhed, F. (2018) Microbial regulation of the L cell transcriptome. Sci Rep, 8, 1207.

Balay, S.D., Widen, S.A., and Waskiewicz, A.J. (2020) Analysis of zebrafish cryptochrome2 and 4 expression in UV cone photoreceptors. Gene Expr Patterns, 35, 119100.

Bates, J.M., Akerlund, J., Mittge, E., and Guillemin, K. (2007) Intestinal alkaline phosphatase detoxifies lipopolysaccharide and prevents inflammation in zebrafish in response to the gut microbiota. Cell Host Microbe, 2, 371-382.

Bates, J.M., Mittge, E., Kuhlman, J., Baden, K.N., Cheesman, S.E., and Guillemin, K. (2006) Distinct signals from the microbiota promote different aspects of zebrafish gut differentiation. Dev Biol, 297, 374-386. Belkaid, Y., and Hand, T.W. (2014) Role of the microbiota in immunity and inflammation. Cell, 157, 121141.

Brugman, S. (2016) The zebrafish as a model to study intestinal inflammation. Dev Comp Immunol, 64, $82-92$.

Buchon, N., Broderick, N.A., Chakrabarti, S., and Lemaitre, B. (2009) Invasive and indigenous microbiota impact intestinal stem cell activity through multiple pathways in Drosophila. Genes Dev, 23, 2333-2344. Butler, A., Hoffman, P., Smibert, P., Papalexi, E., and Satija, R. (2018) Integrating single-cell transcriptomic data across different conditions, technologies, and species. Nat Biotechnol, 36, 411-420.

Cheesman, S.E., Neal, J.T., Mittge, E., Seredick, B.M., and Guillemin, K. (2011) Epithelial cell proliferation in the developing zebrafish intestine is regulated by the Wnt pathway and microbial signaling via Myd88. Proc Natl Acad Sci U S A, 108 Suppl 1, 4570-4577.

Chen, H., Albergante, L., Hsu, J.Y., Lareau, C.A., Lo Bosco, G., Guan, J., Zhou, S., Gorban, A.N., Bauer, D.E., Aryee, M.J. et al. (2019) Single-cell trajectories reconstruction, exploration and mapping of omics data with STREAM. Nat Commun, 10, 1903. 
Covassin, L.D., Villefranc, J.A., Kacergis, M.C., Weinstein, B.M., and Lawson, N.D. (2006) Distinct genetic interactions between multiple Vegf receptors are required for development of different blood vessel types in zebrafish. Proc Natl Acad Sci U S A, 103, 6554-6559.

Crosnier, C., Vargesson, N., Gschmeissner, S., Ariza-McNaughton, L., Morrison, A., and Lewis, J. (2005) Delta-Notch signalling controls commitment to a secretory fate in the zebrafish intestine. Development, $132,1093-1104$.

Davison, J.M., Lickwar, C.R., Song, L., Breton, G., Crawford, G.E., and Rawls, J.F. (2017) Microbiota regulate intestinal epithelial gene expression by suppressing the transcription factor Hepatocyte nuclear factor 4 alpha. Genome Res, 27, 1195-1206.

Dillon, A., and Lo, D.D. (2019) M Cells: Intelligent Engineering of Mucosal Immune Surveillance. Front Immunol, 10, 1499.

Dudakov, J.A., Hanash, A.M., and van den Brink, M.R. (2015) Interleukin-22: immunobiology and pathology. Annu Rev Immunol, 33, 747-785.

Eden, E., Navon, R., Steinfeld, I., Lipson, D., and Yakhini, Z. (2009) GOrilla: a tool for discovery and visualization of enriched GO terms in ranked gene lists. BMC Bioinformatics, 10, 48.

Flores, E.M., Nguyen, A.T., Odem, M.A., Eisenhoffer, G.T., and Krachler, A.M. (2020) The zebrafish as a model for gastrointestinal tract-microbe interactions. Cell Microbiol, 22, e13152.

Flores, M.V., Crawford, K.C., Pullin, L.M., Hall, C.J., Crosier, K.E., and Crosier, P.S. (2010) Dual oxidase in the intestinal epithelium of zebrafish larvae has anti-bacterial properties. Biochem Biophys Res Commun, 400, 164-168.

Fuglem, B., Jirillo, E., Bjerkås, I., Kiyono, H., Nochi, T., Yuki, Y., Raida, M., Fischer, U., and Koppang, E.O. (2010) Antigen-sampling cells in the salmonid intestinal epithelium. Dev Comp Immunol, 34, 768-774. 
Galindo-Villegas, J., García-Moreno, D., de Oliveira, S., Meseguer, J., and Mulero, V. (2012) Regulation of immunity and disease resistance by commensal microbes and chromatin modifications during zebrafish development. Proc Natl Acad Sci U S A, 109, E2605-14.

Goi, M., and Childs, S.J. (2016) Patterning mechanisms of the sub-intestinal venous plexus in zebrafish. Dev Biol, 409, 114-128.

Goldberg, R.F., Austen, W.G., Zhang, X., Munene, G., Mostafa, G., Biswas, S., McCormack, M., Eberlin, K.R., Nguyen, J.T., Tatlidede, H.S. et al. (2008) Intestinal alkaline phosphatase is a gut mucosal defense factor maintained by enteral nutrition. Proc Natl Acad Sci U S A, 105, 3551-3556.

Grunwald, D.J., and Eisen, J.S. (2002) Headwaters of the zebrafish -- emergence of a new model vertebrate. Nat Rev Genet, 3, 717-724.

Haegebarth, A., and Clevers, H. (2009) Wnt signaling, Igr5, and stem cells in the intestine and skin. Am J Pathol, 174, 715-721.

Hill, J.H., Franzosa, E.A., Huttenhower, C., and Guillemin, K. (2016) A conserved bacterial protein induces pancreatic beta cell expansion during zebrafish development. Elife, 5, Hirose, K., Shimoda, N., and Kikuchi, Y. (2011) Expression patterns of Igr4 and Igr6 during zebrafish development. Gene Expr Patterns, 11, 378-383.

Hooper, L.V., Wong, M.H., Thelin, A., Hansson, L., Falk, P.G., and Gordon, J.I. (2001) Molecular analysis of commensal host-microbial relationships in the intestine. Science, 291, 881-884.

Isogai, S., Horiguchi, M., and Weinstein, B.M. (2001) The vascular anatomy of the developing zebrafish: an atlas of embryonic and early larval development. Dev Biol, 230, 278-301.

Kanther, M., Sun, X., Mühlbauer, M., Mackey, L.C., Flynn, E.J., Bagnat, M., Jobin, C., and Rawls, J.F. (2011) Microbial colonization induces dynamic temporal and spatial patterns of NF-kB activation in the zebrafish digestive tract. Gastroenterology, 141, 197-207. 
Katzenback, B.A. (2015) Antimicrobial Peptides as Mediators of Innate Immunity in Teleosts. Biology (Basel), 4, 607-639.

Knoop, K.A., Kumar, N., Butler, B.R., Sakthivel, S.K., Taylor, R.T., Nochi, T., Akiba, H., Yagita, H., Kiyono, H., and Williams, I.R. (2009) RANKL is necessary and sufficient to initiate development of antigen-sampling M cells in the intestinal epithelium. J Immunol, 183, 5738-5747.

Koch, B.E.V., Yang, S., Lamers, G., Stougaard, J., and Spaink, H.P. (2018) Intestinal microbiome adjusts the innate immune setpoint during colonization through negative regulation of MyD88. Nat Commun, 9, 4099. Ledford, J.G., Kovarova, M., and Koller, B.H. (2007) Impaired host defense in mice lacking ONZIN. J Immunol, 178, 5132-5143.

Lenard, A., Daetwyler, S., Betz, C., Ellertsdottir, E., Belting, H.G., Huisken, J., and Affolter, M. (2015) Endothelial cell self-fusion during vascular pruning. PLoS Biol, 13, e1002126.

Lickwar, C.R., Camp, J.G., Weiser, M., Cocchiaro, J.L., Kingsley, D.M., Furey, T.S., Sheikh, S.Z., and Rawls, J.F. (2017) Genomic dissection of conserved transcriptional regulation in intestinal epithelial cells. PLoS Biol, 15, e2002054.

Lin, G., Xu, N., and Xi, R. (2008) Paracrine Wingless signalling controls self-renewal of Drosophila intestinal stem cells. Nature, 455, 1119-1123.

Løvmo, S.D., Speth, M.T., Repnik, U., Koppang, E.O., Griffiths, G.W., and Hildahl, J.P. (2017) Translocation of nanoparticles and Mycobacterium marinum across the intestinal epithelium in zebrafish and the role of the mucosal immune system. Dev Comp Immunol, 67, 508-518.

Melancon, E., Gomez De La Torre Canny, S., Sichel, S., Kelly, M., Wiles, T.J., Rawls, J.F., Eisen, J.S., and Guillemin, K. (2017) Best practices for germ-free derivation and gnotobiotic zebrafish husbandry. Methods Cell Biol, 138, 61-100. 
Murdoch, C.C., Espenschied, S.T., Matty, M.A., Mueller, O., Tobin, D.M., and Rawls, J.F. (2019) Intestinal Serum amyloid A suppresses systemic neutrophil activation and bactericidal activity in response to microbiota colonization. PLoS Pathog, 15, e1007381.

Ng, A.N., de Jong-Curtain, T.A., Mawdsley, D.J., White, S.J., Shin, J., Appel, B., Dong, P.D., Stainier, D.Y., and Heath, J.K. (2005) Formation of the digestive system in zebrafish: III. Intestinal epithelium morphogenesis. Dev Biol, 286, 114-135.

Nicenboim, J., Malkinson, G., Lupo, T., Asaf, L., Sela, Y., Mayseless, O., Gibbs-Bar, L., Senderovich, N., Hashimshony, T., Shin, M. et al. (2015) Lymphatic vessels arise from specialized angioblasts within a venous niche. Nature, 522, 56-61.

Nigro, G., Rossi, R., Commere, P.H., Jay, P., and Sansonetti, P.J. (2014) The cytosolic bacterial peptidoglycan sensor Nod2 affords stem cell protection and links microbes to gut epithelial regeneration. Cell Host Microbe, 15, 792-798.

Parikh, K., Antanaviciute, A., Fawkner-Corbett, D., Jagielowicz, M., Aulicino, A., Lagerholm, C., Davis, S., Kinchen, J., Chen, H.H., Alham, N.K. et al. (2019) Colonic epithelial cell diversity in health and inflammatory bowel disease. Nature, 567, 49-55.

Park, J., Levic, D.S., Sumigray, K.D., Bagwell, J., Eroglu, O., Block, C.L., Eroglu, C., Barry, R., Lickwar, C.R., Rawls, J.F. et al. (2019) Lysosome-Rich Enterocytes Mediate Protein Absorption in the Vertebrate Gut. Dev Cell, 51, 7-20.e6.

Pham, L.N., Kanther, M., Semova, I., and Rawls, J.F. (2008) Methods for generating and colonizing gnotobiotic zebrafish. Nat Protoc, 3, 1862-1875.

Rawls, J.F., Samuel, B.S., and Gordon, J.I. (2004) Gnotobiotic zebrafish reveal evolutionarily conserved responses to the gut microbiota. Proc Natl Acad Sci U S A, 101, 4596-4601. 
Reikvam, D.H., Erofeev, A., Sandvik, A., Grcic, V., Jahnsen, F.L., Gaustad, P., McCoy, K.D., Macpherson, A.J., Meza-Zepeda, L.A., and Johansen, F.E. (2011) Depletion of murine intestinal microbiota: effects on gut mucosa and epithelial gene expression. PLoS One, 6, e17996.

Reinhardt, C., Bergentall, M., Greiner, T.U., Schaffner, F., Ostergren-Lundén, G., Petersen, L.C., Ruf, W., and Bäckhed, F. (2012) Tissue factor and PAR1 promote microbiota-induced intestinal vascular remodelling. Nature, 483, 627-631.

Sekirov, I., Russell, S.L., Antunes, L.C., and Finlay, B.B. (2010) Gut microbiota in health and disease. Physiol Rev, 90, 859-904.

Smillie, C.S., Biton, M., Ordovas-Montanes, J., Sullivan, K.M., Burgin, G., Graham, D.B., Herbst, R.H., Rogel, N., Slyper, M., Waldman, J. et al. (2019) Intra- and Inter-cellular Rewiring of the Human Colon during Ulcerative Colitis. Cell, 178, 714-730.e22.

Sonnenburg, J.L., and Bäckhed, F. (2016) Diet-microbiota interactions as moderators of human metabolism. Nature, 535, 56-64.

Stappenbeck, T.S., Hooper, L.V., and Gordon, J.I. (2002) Developmental regulation of intestinal angiogenesis by indigenous microbes via Paneth cells. Proc Natl Acad Sci U S A, 99, 15451-15455.

Stephens, W.Z., Burns, A.R., Stagaman, K., Wong, S., Rawls, J.F., Guillemin, K., and Bohannan, B.J. (2016) The composition of the zebrafish intestinal microbial community varies across development. ISME J, 10, 644-654.

Supek, F., Bošnjak, M., Škunca, N., and Šmuc, T. (2011) REVIGO summarizes and visualizes long lists of gene ontology terms. PLoS One, 6, e21800.

Takeda, K., and Akira, S. (2005) Toll-like receptors in innate immunity. Int Immunol, 17, 1-14.

Troll, J.V., Hamilton, M.K., Abel, M.L., Ganz, J., Bates, J.M., Stephens, W.Z., Melancon, E., van der Vaart, M., Meijer, A.H., Distel, M. et al. (2018) Microbiota promote secretory cell determination in the intestinal epithelium by modulating host Notch signaling. Development, 145, 
Vanuytsel, T., Senger, S., Fasano, A., and Shea-Donohue, T. (2013) Major signaling pathways in intestinal stem cells. Biochim Biophys Acta, 1830, 2410-2426.

Wallace, K.N., Akhter, S., Smith, E.M., Lorent, K., and Pack, M. (2005) Intestinal growth and differentiation in zebrafish. Mech Dev, 122, 157-173.

Wang, Y., Kaiser, M.S., Larson, J.D., Nasevicius, A., Clark, K.J., Wadman, S.A., Roberg-Perez, S.E., Ekker, S.C., Hackett, P.B., McGrail, M. et al. (2010a) Moesin1 and Ve-cadherin are required in endothelial cells during in vivo tubulogenesis. Development, 137, 3119-3128.

Wang, Z., Du, J., Lam, S.H., Mathavan, S., Matsudaira, P., and Gong, Z. (2010b) Morphological and molecular evidence for functional organization along the rostrocaudal axis of the adult zebrafish intestine. BMC Genomics, 11, 392.

Westerfield, M. (2000) The Zebrafish Book. A Guide for the Laboratory Use of Zebrafish (Danio rerio), 4th Edition. University of Oregon Press, Eugene.

Wiles, T.J., Jemielita, M., Baker, R.P., Schlomann, B.H., Logan, S.L., Ganz, J., Melancon, E., Eisen, J.S., Guillemin, K., and Parthasarathy, R. (2016) Host Gut Motility Promotes Competitive Exclusion within a Model Intestinal Microbiota. PLoS Biol, 14, e1002517.

Zitvogel, L., Galluzzi, L., Viaud, S., Vétizou, M., Daillère, R., Merad, M., and Kroemer, G. (2015) Cancer and the gut microbiota: an unexpected link. Sci Transl Med, 7, 271ps1. 